Dyason, K. M., Shanley, D. C., Hawkins, E., Morrissey, S. A., \& Lambert, M. J. (2018). A systematic review of research in psychology training clinics: How far have we come? Training and Education in Professional Psychology, in print. doi: 10.1037/tep0000196

(C) 2018, American Psychological Association. This paper is not the copy of record and may not exactly replicate the final, authoritative version of the article. Please do not copy or cite without authors permission. The final article will be available, upon publication, via its DOI: 10.1037/tep0000196 
A systematic review of research in psychology training clinics:

How far have we come?

\author{
Katelyn M. Dyason \\ Dianne C. Shanley \\ Erinn Hawkins \\ Shirley A. Morrissey \\ Michael J. Lambert
}




\begin{abstract}
Psychology training clinics provide evidence-based, cost-effective psychological services to the general public, while at the same time providing a training ground for future psychotherapists. Research in training clinics can advance the clinical literature, train psychotherapists in evidence-based practice and improve outcomes for clients. However, since the last published review of research published in psychology training clinics (Todd, Kurcias, \& Gloster, 1994), it is unclear how much the training clinic literature has advanced in the last two decades or if findings can be synthesized across sites. A systematic, quantitative literature review with strict inclusion and exclusion criteria described 257 empirical studies conducted in training clinics since the previous review (1993-2015). Studies were coded and categorized into themes by three independent raters. Studies explored the nature and organization of training clinics, client characteristics, assessment, intervention, staff and clinical training, as well as research and research training. Across themes, it appeared that the literature has broadened extensively, highlighting that researchers have embraced training clinics as a sample source. While there was a great breadth of topics researched, there remains insufficient depth in the majority of areas, and a need for multi-site collaborations with a shared research agenda across training clinics. The review highlighted the extent to which training clinics are valuable research locations, although more research is needed to compare different training clinics and between training clinics versus non-training clinics.
\end{abstract}

Keywords: psychology training clinic; systematic review; psychotherapy; trainee psychotherapist; evidence-based training 


\section{A systematic review of research in psychology training clinics: How far have we come?}

Due to their limited intake capacity and academic calendar constraints, psychology training clinics tend to be quiet achievers in mental health service delivery. University-affiliated psychology training clinics provide evidence-based, outcome informed assessment and outpatient psychotherapy to the general public or students, within a supportive training environment including increased supervision for trainee psychotherapists. These training clinics are predominantly serviced by psychology, counseling or marriage and family therapy post-graduate students who are not yet fully licensed, although opportunities for clients to see licensed psychotherapists may also be available within the clinic. Research has shown that psychologists in training are often just as effective as experienced psychologists (Hansen, Lambert, \& Forman, 2002; Nyman, Nafziger, \& Smith, 2010), although they may take a longer to achieve the same results (Callahan \& Hynan, 2005; Reese, Norsworthy, \& Rowlands, 2009). This effectiveness even with limited training may be due to inherent therapist characteristics (Lutz, Leon, Martinovich, Lyons, \& Stiles, 2007; Okiishi et al., 2006), increased supervision (Wheeler \& Richards, 2007), feedback and routine outcome monitoring (Miller, Hubble, Chow, \& Seidel, 2013; Lambert, 2017), purposeful practice (Chow et al., 2015), or a myriad of other factors.

Training clinics may therefore be an interesting and informative setting for answering the oft-debated questions about what makes psychotherapy effective, whether client outcomes can be modified through psychotherapist training, or whether psychotherapeutic qualities can be made and not born. As clientele are community-based, experiencing genuine mental-health problems that they are seeking help for, training clinics can be a useful and available clinical sample for the research community, who are often physically close to the training clinic. Training clinics also offer a high degree of control and standardization from supervision and training, they serve real 
clients with real problems, and they often do not have the strict inclusion/exclusion criteria of randomized controlled trials. Therefore, training clinics may provide a 'middle ground' between effectiveness and efficacy research (Neufeldt \& Nelson, 1998), combining the most desirable aspects from each approach. Conducting research in training clinics offers further benefits to trainees, including training psychotherapists in evidence-based practice, the routine integration of the latest research findings into their clinical practice to provide the best care for clients, the use of scientific methodology, the curiosity to assess their clients and the development of clinically relevant research topics for further investigation.

However, the extent to which both the research and training communities can synthesize and draw from research conducted in training clinics is unknown. The most recent systematic review of the training clinic literature was published in 1994 (Todd, Kurcias, \& Gloster), examining studies published between 1974 and 1992. Clearly, research and training have advanced substantially since this time, but the impact this has had on the training clinic literature is yet to be described. This current review aims to highlight how training clinics are valuable for the research literature and for training the next generation of evidence-based practitioners. It systematically summarises the areas of research conducted in training clinics over the last two decades and highlights where research in training clinics might be able to advance the psychological literature and psychotherapy training.

The previous review of research conducted in psychology training clinics (Todd et al., 1994) included 134 studies, establishing the presence of an extensive literature based on research conducted in training clinics. It highlighted an enormous diversity with respect to the nature, staffing and training in clinics and it was clear that these factors required more systematic and detailed descriptions. However, 36 of the studies included in the review contained no explicit 
reference to being conducted in a training clinic. The authors recommended that although training clinic research can, and has, contributed to clinical knowledge, there was still not much known about the clients, services offered and the nature of the clinics themselves, or about the training offered in clinics. Several suggestions were posited to remedy this deficit in the literature: expanding beyond one specific research topic; including contextual information about the clinic and training practices; describing how participant samples compare to the population the clinic serves; comparing what differentiates training clinic environments from each other, such as by differences in service or training, and how these differences might relate to clinical outcomes; encouraging collaboration between training clinics and pooling data across settings; and, most importantly, specifically identifying that research is conducted in a training clinic.

In addition, there were few examples of how research and practice could be integrated within a training environment: an aspect the authors considered particularly achievable given the unique environment of training clinics. The review concluded that due to the diversity of training clinics, the ability to generalize across studies and draw conclusions about 'training clinics' in general was unlikely. To consider generalizations across studies, an explicit statement that the research was conducted in a training clinic, along with clearer descriptions of the clinic environments and the variables being researched were required. They further concluded that more research was needed to determine the effectiveness of services provided in training clinics.

\section{Aim of the Current Research}

The aim of the current study was to conduct a systematic literature review (from 1993 2015) of the published research conducted in psychology training clinics since the last systematic review (Todd et al., 1994). The current review aimed to highlight the recent topics that have been covered by research in training clinics, to reveal topics that have not yet been studied and to 
determine whether Todd et al.'s (1994) recommendations were implemented over the next two decades. A systematic quantitative review allows for reproduction, as its methodology is explicit; it reduces bias by aiming to cover all extant literature meeting eligibility criteria; and it provides richer, more detailed information than a traditional systematic narrative review (Pickering \& Byrne, 2014). It is also ideal for situations where meta-analyses are not possible due to the diverse methodology or topics covered by the examined research (Pickering \& Byrne, 2014). This quantitative methodology highlights areas where research has already provided useful conclusions, but also highlights gaps in the literature, which can be addressed in future research (Pickering \& Byrne, 2014).

\section{Method}

\section{Eligibility Criteria}

Inclusion criteria for studies were: (a) research conducted in a psychology outpatient training clinic (including outpatient clinics servicing only students, such as university counselling centers), (b) use of trainee psychotherapists, (c) original empirical research studies, (d) published in English, and (e) published between 1993 and 2015. Exclusion criteria for studies were: (a) psychiatric studies, including psychoanalytical studies in medical faculties (medical training and treatment is very different to psychological training and treatment), (b) studies published in a language other than English, and (c) non-empirical articles (e.g., descriptive case studies, discussion / commentary articles). It was not possible to differentiate between training clinics that offered first placement practicum and those who offered subsequent practicums, so practicum number was not used an inclusion or exclusion criteria.

Psychoanalytic studies were retained if these studies utilized trainee psychology therapists; and studies involving trainee psychiatry therapists were retained if trainee psychology 
therapists were also included in the same study (i.e., some training clinics provide training opportunities for both trainee psychologists and trainee psychiatrists). Disciplines involving overlapping training with psychology (e.g., counselling, marriage/family therapy etc.) were also retained. Any clinic utilizing a majority of trainee psychotherapists was retained, as it was often difficult to distinguish between 'training clinics' and clinics where training opportunities are provided (e.g. university counselling centers utilizing trainee psychotherapists). Unpublished dissertations were retained unless they had since been published, in which case the journal article was included and the dissertation excluded.

\section{Search Methods and Data Collection}

Using similar but expanded search terms to Todd et al. (1994), searches were conducted in both the PsycINFO and PubMed databases using the keywords of [(psycho*) AND (training clinic OR university clinic OR training centre OR training center OR university center OR university centre OR department clinic)] in English language for the period of January 1993 to December 2015, resulting in 367 and 208 studies, respectively. Results from the two databases were combined and duplicates removed, leaving 550 studies. After reviewing study titles and abstracts, 308 studies were excluded for not meeting inclusion criteria. Upon review of the 242 articles whose full-texts were examined to determine eligibility, 99 articles were found to meet inclusion criteria and were eligible for inclusion in this review. A further 139 articles were excluded due to not meeting inclusion criteria, and four articles were unable to be accessed because they were dissertations only available in hard-copy at their universities. One dissertation was excluded and the published paper resulting from the dissertation was instead included.

The authors supplemented the findings from the systematic search with their knowledge of other published studies that had been conducted in university training clinics and by reviewing 
the reference lists of previously identified studies $(N=53)$. The authors then hand-searched the abstracts from all articles (1993-2015) of journals that had published two or more studies thus far included in the review ( $N=20$ journals; see online supplemental information) and one other recommended journal (The Clinical Supervisor). This identified a further 105 studies; thus, a total of 257 studies were included in this review.

\section{Data Analysis}

Todd et al.'s (1994) original broad categories of research topics were expanded in this review to address current uses of training clinic data. New topics were added to Todd et al.'s (1994) original list of topics prior to reviewing any studies. This original list therefore comprised topics that could be studied in the training clinic environment. A sub-set of studies were then reviewed according to this new list. This new list was expanded to include topics that were included in the sub-set of studies but not in the original list of topics. While the list of topics was not exhaustive, it represented all topics included in this review, and additional topics that were not examined in this review.

Three of the authors independently categorized all studies with up to three categories that best represented the topics under study in each article. Only the main aims and findings from studies were coded to determine where the training clinic literature was focused. All three raters agreed on at least one topic for $68.1 \%$ of articles; whereas, two raters agreed on at least one topic for $96.5 \%$ of articles. All raters then discussed each article until there was $100 \%$ agreement on categorization of topics for each article. Differences in ratings were usually due to coding error or to slightly different interpretations of categories rather than true disagreement, and thus discrepancies were easily resolved.

\section{Results}




\section{Characteristics of Studies}

The 257 studies were published across 12 different countries and included 228 journal articles and 29 dissertations. The USA contributed the majority of studies to the review (83.7\% of studies and all 29 dissertations), followed by Australia (4.7\%) and Canada (2.7\%). The 123 journal articles were published in 58 different journals. The most popular journals were Psychotherapy/Psychotherapy: Theory, Research, Practice, Training (change of name in journal); Training and Education in Professional Psychology; Psychotherapy Research; Journal of Counseling Psychology; Journal of Clinical Psychology; and The American Journal of Family Therapy. The number of studies based on research in training clinics increased substantially over the examined period, with $50 \%$ of studies being published in 2009 or later. The majority of studies $(91.8 \%)$ used a quantitative methodology. For more detailed information, please see the online supplemental material.

Most studies (80.9\%) utilized clinic clients as their sample. Of these 208 studies, the majority (73.6\%) used an adult and/or university student population exclusively, and only $10.6 \%$ used a child/adolescent population exclusively (see online supplemental material). Client sample size ranged from 3 to 6099 clients. Eight studies did not report a specific participant sample size, as they combined individuals, couples and groups, reporting only on the number of participant units included; two studies predominantly utilizing psychotherapist participants also reported client sample size. When three very large samples were removed as outliers $(N=6099, N=4676$ and $N=1930)$, the mean number of client participants in a study was $187.40(S D=227.79$; range $=3-1318 ; N=199$ studies). However, the sample was significantly positively skewed, with $50 \%$ of the studies having sample sizes of 95 or fewer. Of the studies reporting the number of participating psychotherapists $(n=130)$, the mean number of psychotherapists in a study was 
$50.59(S D=51.41$; range $=2-294)$, although again the sample was positively skewed with $50 \%$ of the studies having psychotherapist sample sizes of 32 or fewer. Of the studies reporting the number of participating supervisors or other staff $(n=35)$, the mean number of participants in a study was $42.97(S D=65.14$; range $=3-328)$ with $50 \%$ of the studies utilizing 18 supervisors/staff members. Sample size did not significantly increase or decrease over the publication period studied for client $(r=0.40, p=.58)$, therapist $(r=0.13, p=.15)$ or supervisor/staff participants $(r=0.04, p=.84)$.

Theoretical orientation was reported in $81.3 \%$ of the studies $(n=209)$. The majority $(n=$ 74 studies) reported operating from either an eclectic therapeutic perspective, or from at least two different therapeutic orientations. Of studies reporting only two therapeutic orientations, cognitive-behavioral therapy (CBT), psychodynamic, interpersonal psychotherapy and acceptance and commitment therapy (ACT) were most common $(n>1)$. Of studies that reported only one theoretical orientation, Counselling/Counseling Psychology, Couple/Marriage and Family Therapy, CBT and psychodynamic were the most frequently reported therapeutic approaches utilized. It is worth noting that 44 studies $(17.1 \%)$ did not report the type of psychotherapy provided to clients, and four studies did not conduct psychotherapy $(1.6 \%)$.

\section{Research Topics within Studies}

Research topics were diverse and varied. The frequency of research topics studied is shown in Table 1. Thirty-eight different research topics were included and examined for their frequency. Just under half of the studies $(49.4 \% ; n=127)$ focused on a single topic. However, many studies researched more than one topic, with 99 studies $(38.5 \%)$ examining two topics concurrently, and 31 studies (12.1\%) examining three topics. The most studied research topics were understanding working alliance, predictors of dropout, supervision, clinical training and 
competency, psychotherapy process and patterns of response to psychotherapy. Five research topics were only examined once across all studies. Only two potential areas for research generated by the authors were not found in this review of the literature (the scientist-practitioner model and research training).

Whilst research into each broad category increased over the period examined in the current review (see Figure 1), consistent with the general increase in interest in publishing data from training clinics, there was more increase in studies looking broadly at research and research training, staff and clinical training, and intervention. The current review included significantly more research in area of client characteristics, $\chi^{2}(1, \mathrm{n}=551)=4.47, p=.03$; significantly less research into the nature and organisation of training clinics, $\chi^{2}(1, \mathrm{n}=551)=4.10, p=.04$, assessment, $\chi^{2}(1, \mathrm{n}=551)=3.91, p=.048$, and research and research training, $\chi^{2}(1, \mathrm{n}=551)=$ $10.87, p<.001$; and the same amount of studies in the areas of interventions, $\chi^{2}(1, \mathrm{n}=551)=$ $3.76, p=.053$ and staff and clinical training, $\chi^{2}(1, \mathrm{n}=551)=0.57, p=.45$.

\section{Discussion}

Over twenty years ago, Todd et al. (1994) advocated for the research community to utilize training clinics as a method of fully integrating science and practice. The current study appears to show that research interest in psychology training clinics has indeed grown substantially (257 studies over a 22-year period, compared to the previous 134 studies over an 18-year period), suggesting that researchers are utilizing the training clinic as a valuable setting for research. The largest area of research was into intervention, as it was in Todd et al.'s (1994) review, comprising almost half of the topics covered. Again, like the previous review, the least studied areas were research and research training, and client characteristics. In this regard, despite utilizing training clinic research, the literature does not seem to have advanced according to Todd et al.'s (1994) 
recommendations to better understand the nature of training clinics to understand the contribution they can make to clinical knowledge.

In addition, we do not know much about differences between training clinics and nontraining clinics, and whether the findings from training clinics can be applied to non-training settings. The studies in this review that compared trainee psychotherapists to registered psychotherapists found that while trainees improved in effectiveness over the course of their training (Driscoll et al., 2003; Hill et al., 2015; Powell, Hunter, Beasley, \& Vernberg, 2010; Reese, Usher et al., 2009), they can still be as effective as registered psychotherapists (Nyman et al., 2010). The preliminary findings are therefore promising that training clinic research can be applied outside of the training environment, but it is premature to apply these findings yet, without more understanding of how psychotherapist competence changes over the course of their training, and how other dimensions of training, such as increased supervision or reduced caseload, might also influence psychotherapy process and outcome. These findings combined with the literature which demonstrates that psychotherapist effectiveness can be improved even after registration - through avenues such as routine outcome monitoring, seeking feedback from clients, purposeful practice and a focus on the working alliance (e.g. Chow et al., 2015; Miller et al., 2013; Lambert, 2017) - highlights the need for ongoing training of clinicians and controlling for these factors when examining psychotherapist outcomes in non-training environments.

Todd et al. (1994) recommended that to advance the literature, several methods should be employed: expanding beyond one specific research topic; including contextual information about the clinic and training practices; describing how participant samples compare to the population the clinic serves; comparing what differentiates training clinic environments from each other, such as by differences in service or training, and how these differences might relate to clinical 
outcomes; encouraging collaboration between training clinics and pooling data across settings; and, most importantly, specifically identifying that research is conducted in a training clinic. Some of these recommendations appear to have been followed. For instance, just over half of the studies examined two or more research topics concurrently, helping to grow the literature on relationships between variables. Collaboration between training clinics was rare, but has occurred sporadically. However, the implementation of this recommendation may occur in the not too distant future: Callahan et al. (2014) and McAleavey, Lockard, Castonguay, Hayes, and Locke (2015) have proposed a collaborative research network for psychology training clinics and university and college counselling centers in the United States. If successful, collaboration between training clinics could not only boost sample size, but a shared, programmatic agenda for research topics could be developed. This agenda could address the need for deeper exploration of research topics to allow more generalizable conclusions to be drawn and to compare aspects of training that may lead to better client outcomes, or psychotherapist competence. This will be especially likely if training clinics adapt the growing practice of providing psychotherapists feedback based on monitoring client treatment response — so-called routine outcome monitoring (Lambert, 2017).

Some of Todd et al.'s (1994) recommendations could still be easily implemented. The majority of studies did not include in-depth description of the clinic and did not compare their sample with the clinic population; and except for studies specifically examining clinical training and competence, most did not report any aspects of training, and even within those examining clinical training and competence, many did not report beyond their specific study's focus. Studies that collaborated across training clinic sites did not compare the sites beyond differences in the variables that were examined. We reiterate these recommendations of including description of the 
clinic and training, and how the study fits into the broader environment of the clinic and the population it serves. These descriptions would be especially important in multi-site collaborations, or if conducting a meta-analysis of findings across sites. The implications of this for advancing the training of future psychotherapists would be valuable if it sheds light on what training practices promote psychotherapist competence and better outcomes for clients.

Obviously, the extent to which researchers are not explicitly stating that research is conducted in a training clinic is unknown merely by a literature search. One method to overcome this could be to contact training clinic directors and ask for a list of all the studies that have been conducted within their clinic, within the context of a review. However, utilizing listservs for this purpose would be country-specific, and may still miss studies that the clinic directors are unaware of, such as studies conducted before their involvement in the clinic. This remains a difficult recommendation to test, but the inclusion of descriptions of the setting of research is valuable outside the training clinic environment too, so we again reiterate the importance of researchers identifying that their research is conducted in a training clinic and describing the clinic environment.

Within the six broad categories, studies covered an ample breadth of research topics, highlighting the diversity of the training clinic environment. However, there appeared to be few topics that have been studied in sufficient depth to draw general conclusions, such as with metaanalytic techniques. Therefore, we chose not to report effect sizes or strength of relationships. Two well-researched areas that may warrant meta-analyses were predictors of dropout (premature termination) and understanding working alliance, and results relating to efficacy of specific treatments and of the overall clinic may also warrant meta-analyses. Meta-analyses of findings from training clinics could not only be used to determine the effectiveness of training clinics, but 
could also be compared to standardized findings in other settings and could determine how applicable the findings from the training environment might be to non-training environments.

For this to occur and the literature to advance, there needs to be consistency in definitions and statistical methodologies. For example, if researchers were to consistently use the two definitions for clinically meaningful change proposed by Jacobson and Truax (1991) - namely, one that considers amount of change (the reliable change index) and one that considers a return to normal functioning - then results may be more directly compared given the wide array of research variables and topics covered.

Only two randomised controlled trials were identified as being conducted in a training clinic. This suggests several possibilities: that training clinics are not well-suited to conducting RCTs; that training clinics are being underutilized for this purpose; or that studies are not reporting that they are using a university training clinic with trainee psychotherapists in their manuscripts. Additionally, many plausible topics such as continuity of care, evidence-based assessment, ethics, interprofessional learning, and various therapist predictors of outcome were only investigated by one or two studies each. Whilst the scientist-practitioner model and research training were not explicitly investigated by a single study, it could be argued that whilst this was not an explicit goal of other studies, it was implicit in the design and orchestration of most other studies.

The review also highlighted that research has been conducted internationally and accepted by a vast number of journals. Unfortunately, this information was not available for the previous review, so we do not know if the spread of training clinic research internationally has changed over the past two decades, or indeed if the acceptability of training clinic research to journals has either. Interestingly, the current review highlighted that the USA is the main contributor to the 
training clinic literature, followed by Australia (in English-language publications); and there were a number of topic areas that had not been researched outside of the USA. Given that the training of professional psychologists differs dramatically in these countries and that there are few studies emanating from other parts of the world, it is important to consider how this influences the literature. It may be that there is greater endorsement for evidence-based care and training in the USA and Australia, or that training clinics are more commonplace in the training pathway. It is highly recommended that training clinics in other countries consider publishing data to enhance our understanding of how culture can influence findings. It is of course possible to extrapolate from other clinical findings conducted cross-culturally, but given that training and licensing/registration requirements are vastly different internationally, training clinics are likely also to be different, and an investigation of international differences in training and in training clinics would be a welcome addition to the literature.

Although not common, large sample sizes have been achieved, usually through collating across years or between universities. Interestingly, even with the advent of the Internet and easy file-sharing, sample sizes did not increase over the period studied. Most studies used clinic clients as their participants, particularly adult or student client populations. There were a limited number of studies utilizing child or adolescent clients, and likely not enough within a single category to make valid assumptions about this population in training clinics. It may be that youth are not as commonly seen in training clinic environments, but more research needs to be published with youth participants to accurately understand trainee psychotherapists' competencies with youth, and the unique dynamic that youth bring to the psychotherapy environment. This may also highlight that trainee psychotherapists are not receiving adequate exposure to working with youth prior to completing practicum placements outside the university. Additionally, there were several 
studies that did not report the type of client sample used, or did not report the specific number of participants included. These are limitations that should be addressed and easily overcome in future research. Similarly, there were a significant number of studies that did not report what therapy was provided to clients, or what the theoretical orientation of the clinic was. Of those that did, the majority reported an eclectic orientation or multiple orientations, consistent with the view that psychotherapy should be adapted to each unique client and their presenting problems.

\section{Limitations}

Despite our systematic search methods, we acknowledge there may be more studies that were not identified as being conducted in a training clinic, and thus were not included in the review. We chose to retain the same keywords and search methods used by Todd et al. (1994), albeit broadened, except contacting training clinic directors to identify further studies. Todd et al.'s (1994) methodology for utilizing listservs asked training clinic directors to confirm or add studies that their clinic had published. The decision to not utilize listservs to contact clinic directors was made to not bias the results towards any one country, as listservs are generally country-specific. However, asking clinic directors to add research that has been published in their clinic or elsewhere would have been helpful. Should this review be updated again in the future, we recommend this as a valuable step to uncover as many training clinic studies as possible.

This means there may be studies that explicitly stated that they were conducted in a training clinic, for example in their methodology, which were not identified through our search methods. For example, 53 studies were included from the authors' knowledge and stated that they were conducted in a training clinic; however, these were studies that were not identifiable with our initial search method. Whilst the inclusion of studies from the authors' knowledge increased the number of studies available to review, it also deviated from the systematic search 
methodology. It may have also biased the topics covered, as the majority of the studies fell within the intervention topic area, which may have inflated the proportion of studies examining intervention topics to the detriment of other areas if the authors' knowledge-base had have been in a different area. Other researchers may therefore find that works they consider relevant to the training clinic literature were not identified, and thus, this review may not be representative of all the research that might be possible in a training clinic environment.

Even within the included studies, it was often difficult to differentiate whether the studies were conducted in a psychology department training clinic, a research clinic based at a university utilizing trainee psychotherapists, or a student services clinic with training placements offered. It was also very difficult to determine whether the clinic provided training for first practicum students or students completing their second or third practicum. The training environment is also different across countries, and as such, the authors may have wrongly identified some clinics as being 'training clinics' by including university-affiliated clinics with the majority of psychotherapists still in training; but some countries may not consider these to be 'training clinics', and the population of clinics included may not have been as homogenous as was intended for the review. We reiterate Todd et al.'s (1994) recommendation that researchers need to identify explicitly in the manuscript and abstract when research is conducted in a training clinic and provide a detailed description of the practicum placement and training provided.

A second limitation is that only studies that were published in English were included, possibly excluding valuable research from non-English speaking countries. This again may have influenced conclusions drawn from the literature. A multilingual team would be invaluable in conducting this task and updating the current review. Again, given that training differs across countries, it would be valuable to be able to compare different training practices and registration 
requirements; however, this is not currently possible with the small number of studies found from outside the USA.

A third limitation is that it was outside of the scope of this review to determine how many individual clinics contributed research to this review. Whilst the volume of different authors indicates that it is unlikely that only a few highly-productive training clinics are contributing to the literature, the increase in number of studies may be due to more widespread utilization of training clinics, an increase in the base-rates of training clinics, or the broadening of the search strategy for the current review casting a larger net in the literature (Todd et al., 1994).

Finally, this review was unable to fully describe and compare all studies to draw conclusions about the training clinic environment, due to the number and diversity of studies included. We hope that this review serves as a starting point for future research to take smaller sections of the training clinic literature, and to conduct more in-depth analyses in specific topic areas. These in-depth analyses would be necessary before the training clinic literature could be compared to the findings in the general psychotherapy literature.

\section{Implications and practical significance of this review}

Training clinics are often costly to universities and there is often a demand for training clinics to reduce spending or to bring in funds to help support their activities. Good research can attract significant funding, which might be one way to make training clinics more relevant to universities' mission and more attractive to the university finance teams. If high impact publications emerge from data collected in training clinics, the clinics and their staff become more valuable to the university. This review highlights that it is indeed possible to conduct research in training clinics, and a vast number of clinics do utilize this option; even using their research to address a number of topics in psychology, not just about the nature of the training 
environment. However, the extent to which outcomes from training clinics are consistent or divergent from typical community mental health practices with licensed psychologists is still unknown: this could be a valuable research area for future systematic reviews or meta-analyses. Additionally, other authors (e.g. Borkovec, 2004; Gard, Tremblay, DiLillo, \& Pantesco, 2002; Neufeldt \& Nelson, 1998) have outlined the benefits that conducting research in training clinics can have on training the next generation of evidence-based practitioners to fully integrate research into their practice and their clinical knowledge into research. If this integration occurs from the outset of training, it may be more likely to be integrated after completion of training as barriers to practitioners integrating research may be due to a lack of training, or to not seeing the relevance to their practice (Neufeldt \& Nelson, 1998). However, research is finding that the most effective psychotherapists are those who engage in deliberate practice (Chow et al., 2015), integrating feedback and routine evaluation of outcomes into their practice (Miller et al., 2013): skills which can be developed through training in research and evidence-based care. Thus, if the eventual goal of training is to make the most effective psychotherapists who can alleviate distress for their clients, bringing research into training clinics may be seen as an integral part of training.

The current review highlighted that many training clinics can achieve adequate sample sizes by collating data across years or between universities. Technological limitations may have made such collaborations challenging two decades ago when Todd et al.'s (1994) review was conducted; however, with the advent of secure cloud-based file sharing and patient management systems, collapsing data has become easier and more common. Collaborative research networks (Callahan et al., 2014; McAleavey et al., 2015) could not only boost sample size, but a shared, programmatic agenda for research topics could be developed. This agenda could address the need 
for deeper exploration of research topics to allow more generalizable conclusions to be drawn and comparisons between training practices to be conducted.

Results from our review highlight that a shared agenda could involve several currently under-researched topics, such as: continuity of care (particularly for clients of psychotherapists who complete their practicum before the client finishes psychotherapy), evidence-based assessment, ethics, interprofessional learning and therapist predictors of outcome. Another research topic well suited for training clinics is competency. Our review demonstrated that in general, psychotherapists in training clinics are effective, but previous research has also highlighted that not all psychotherapists are equally effective (e.g. Kraus, Castonguay, Boswell, Nordberg, \& Hayes, 2011). With a trend towards formulating nationally and internationally recognised competencies during training, training clinics would be the ideal environment to examine what makes psychotherapists effective, how to best assess competencies, and how to enhance and maximise supervision. These are just some interesting avenues for future research.

\section{Conclusions}

So, how far has the psychology training clinic literature come over the past two decades? It appears definite progress has been made and the training clinic has been embraced as a research environment, but there is still much progress to be made, specifically to advance the training of future psychotherapists and to understand the contribution that the training clinic literature can make to the general psychotherapy literature. The current review demonstrated that the number of training clinics publishing research has increased substantially, but there is still much to learn about the unique training environment and comparing training clinics with nontraining environments. Whilst the shift towards exploring clinical topics is commendable and vital, researchers must not neglect the valuable questions about training that still need to be 
answered, which are perhaps only answerable in a training clinic. Multi-site collaboration between training clinics with a shared research agenda would be beneficial (Callahan et al., 2014; McAleavey et al., 2015) and between training clinics and non-training clinics to compare different aspects of training, and how the training environment differs.

Training clinics are a valuable asset to both the research and training communities, and to the clients for whom they provide services. If training clinics are regularly evaluating their outcomes and seeking feedback, then routinely collected data can be studied, with the eventual goal of informing better practices for clients and better training of psychotherapists (Miller et al., 2013; Lambert, 2017). Research can be seen as an integral part of treatment and training and when research principles are implemented in a standardized way across all clients and psychotherapists (Sauer, 2006), it need not be expensive nor compromise treatment; and it may even be beneficial to clients' experiences in psychotherapy (Miller et al., 2013; Sauer, 2006; Sauer \& Huber, 2007). For research purposes, training clinics may be the perfect balance between the "clinical context" of effectiveness research and the "research context" of efficacy research (Neufeldt \& Nelson, 1998), with a variety of data easily available to researchers after ethical approval. For training purposes, research can inform learning experiences and train practitioners to provide evidence-based care. For clients, research and routine outcome monitoring may even improve their outcomes and experience of psychotherapy (Miller et al., 2013; Lambert, 2017). 


\section{References}

References marked with an asterisk indicate studies included in the systematic review.

*Abney, P. C. (2002). A study of the relationship between the levels of self-awareness within students enrolled in counseling practicum and the measurements of their counseling effectiveness. (Doctor of Philosophy Dissertation). Available from Ovid Technologies ProQuest Dissertations Publishing database.

*Allan, J., O'Meara, P., Pope, R., Higgs, J., \& Kent, J. (2011). The role of context in establishing clinics. Health and Social Care in the Community, 19, 217-224. doi:10.1111/j.13652524.2010.00971.x

*Allan, J., Pope, R., O'Meara, P., Higgs, J., \& Kent, J. (2011). Serving inland rural communities through university clinics. Health Education Journal, 70, 475-480. doi:10.1177/0017896911403209

*Allgood, S. M., Parham, K. B., Salts, C. J., \& Smith, T. A. (1995). The association between pretreatment change and unplanned termination in family therapy. The American Journal of Family Therapy, 23(3), 195-202. doi:10.1080/01926189508251350

*Anderson, E. M., \& Lambert, M. J. (2001). A survival analysis of clinically significant change in outpatient psychotherapy. Journal of Clinical Psychology, 57, 875-888. doi:10.1002/jclp. 1056

*Aubry, T. D., Hunsley, J., Josephson, G., \& Vito, D. (2000). Quid pro quo: Fee for services delivered in a psychology training clinic. Journal of Clinical Psychology, 56, 23-31. doi:10.1002/(SICI)1097-4679(200001)56:1<23::AID-JCLP3>3.0.CO;2-8 
*Aubuchon-Endsley, N., \& Callahan, J. L. (2014). Exploring pretreatment expectancies in a campus mental health setting: The validation of a novel expectancies measure. Journal of College Counseling, 17, 64-79. doi:10.1002/j.2161-1882.2014.00048.x

*Aubuchon-Endsley, N. L., \& Callahan, J. L. (2009). The hour of departure: Predicting attrition in the training clinic from role expectancies. Training and Education in Professional Psychology, 3, 120-126. doi:10.1037/a0014455

*Axelrad, M. E., Pendley, J. S., Miller, D. L., \& Tynan, W. (2008). Implementation of effective treatments of preschool behavior problems in a clinic setting. Journal of Clinical Psychology in Medical Settings, 15, 120-126. doi:10.1007/s10880-008-9110-2

*Babbage, D. R. (2008). Psychology training clinics in Australia and New Zealand: Clinic structure. Australian Psychologist, 43, 257-277. doi:10.1080/00050060802413354

*Bados, A., Balaguer, G., \& Saldaña, C. (2007). The efficacy of cognitive-behavioral therapy and the problem of drop-out. Journal of Clinical Psychology, 63, 585-592. doi:10.1002/jclp.20368

*Baldwin, S. A., Berkeljon, A., Atkins, D. C., Olsen, J. A., \& Nielsen, S. L. (2009). Rates of change in naturalistic psychotherapy: Contrasting dose-effect and good-enough level models of change. Journal of Consulting and Clinical Psychology, 77, 203-211. doi:10.1037/a0015235

*Barrett, M. S., \& Berman, J. S. (2001). Is psychotherapy more effective when therapists disclose information about themselves? Journal of Consulting \& Clinical Psychology, 69, 597603. doi:10.1037/0022-006X.69.4.597

*Barry, T. D., Klinger, L. G., Lee, J. M., Palardy, N., Gilmore, T., \& Bodin, S. D. (2003). Examining the effectiveness of an outpatient clinic-based social skills group for high 
functioning children with autism. Journal of Autism and Developmental Disorders, 33, 685-701. doi:10.1023/B:JADD.0000006004.86556.e0

*Bartle-Haring, S., Glade, A. C., \& Vira, R. (2005). Initial levels of differentation and reduction in psychological symptoms for clients in marriage and family therapy. Journal of Marital and Family Therapy, 31, 121-131. doi:10.1111/j.1752-0606.2005.tb01548.x

*Bartle-Haring, S., Glebova, T., Gangamma, R., Grafsky, E., \& Delaney, R. (2012). Alliance and termination status in couple therapy: A comparison of methods for assessing discrepancies. Psychotherapy Research, 22, 502-514. doi:10.1080/10503307.2012.676985

*Bartle-Haring, S., Glebova, T., \& Meyer, K. (2007). Premature termination in Marriage and Family Therapy within a Bowenian perspective. The American Journal of Family Therapy, 35, 53-68. doi:10.1080/01926180600550528

*Bartle-Haring, S., Knerr, M., Adkins, K., Delaney, R. O., Gangamma, R., Glebova, T., .. . Meyer, K. (2012). Trajectories of therapeutic alliance in couple versus individual therapy: Three-level models. Journal of Sex \& Marital Therapy, 38, 79-107. doi:10.1080/0092623X.2011.569635

*Bartle-Haring, S., \& Probst, D. (2004). A test of Bowen Theory: Emotional reactivity and psychological distress in a clinical sample. The American Journal of Family Therapy, 32(5), 419-435. doi:10.1080/01926180490455105

*Bartoi, M. G., Issner, J. B., Hetterscheidt, L., January, A. M., Kuentzel, J. G., \& Barnett, D. (2015). Attention problems and stability of WISC-IV scores among clinically referred children. Applied Neuropsychology: Child, 4(3), 133-140.

doi:10.1080/21622965.2013.811075 
*Bieschke, K. J., Bowman, G. D., Hopkins, M., Levine, H., \& McFadden, K. (1995). Improvement and satisfaction with short-term therapy at a university counseling center. Journal of College Student Development, 36, 553-559.

*Blumer, M. L. C., Nemecek, R. T. L., Hertlein, K. M., Rogers, K. R., Weeks, G. R., Peterson, C. M., \& Fife, S. T. (2014). Counseling the unemployed: Exploring MFT trainees’ perceptions of a pilot clinical program. The American Journal of Family Therapy, 42, 205-216. doi:10.1080/01926187.2013.810067

*Boëthius, S. B., Ögren, M.-L., Sjøvold, E., \& Sundin, E. C. (2004). Experiences of group culture and patterns of interaction in psychotherapy supervision groups. The Clinical Supervisor, 23(1), 101-120. doi:10.1300/J001v23n01_07

Borkovec, T. D. (2004). Research in training clinics and practice research networks: A route to the integration of science and practice. Clinical Psychology: Science and Practice, 11, 211-215. doi:10.1093/clipsy.bph073

*Boswell, J. F., Castonguay, L. G., \& Wasserman, R. H. (2010). Effects of psychotherapy training and intervention use on session outcome. Journal of Consulting and Clinical Psychology, 78, 717-723. doi:10.1037/a0020088

*Braga, R. (2014). Client and therapist personality characteristics affecting psychotherapy dropout at a psychological training clinic. (Doctor of Philosophy), Long Island University. Available from Ovid Technologies Dissertation Abstracts International: Section B: The Sciences and Engineering database.

*Brown, C., Murdock, N. L., \& Abels, A. (2014). Ethical issues associated with training in university counseling centers. Training and Education in Professional Psychology, 8, 269-276. doi:10.1037/tep0000063 
*Brown, M., Banford, A., Mansfield, T., Smith, D., Whiting, J., \& Ivey, D. (2012). Posttraumatic stress symptoms and perceived relationship safety as predictors of dyadic adjustment: A test of mediation and moderation. The American Journal of Family Therapy, 40, 349-362. doi:10.1080/01926187.2011.611784

*Budge, S. L., Owen, J. J., Kopta, S. M., Minami, T., Hanson, M. R., \& Hirsch, G. (2013). Differences among trainees in client outcomes associated with the phase model of change. Psychotherapy, 50, 150-157. doi:10.1037/a0029565

*Byrd, K. R., Patterson, C. L., \& Turchik, J. A. (2010). Working alliance as a mediator of client attachment dimensions and psychotherapy outcome. Psychotherapy: Theory, Research, Practice, Training, 47, 631-636. doi:10.1037/a0022080

*Callahan, J. L., Almstrom, C. M., Swift, J. K., Borja, S. E., \& Heath, C. J. (2009). Exploring the contribution of supervisors to intervention outcomes. Training and Education in Professional Psychology, 3, 72-77. doi:10.1037/a0014294

*Callahan, J. L., Aubuchon-Endsley, N., Borja, S. E., \& Swift, J. K. (2009). Pretreatment expectancies and premature termination in a training clinic environment. Training and Education in Professional Psychology, 3, 111-119. doi:10.1037/a0012901

*Callahan, J. L., Gustafson, S. A., Misner, J. B., Paprocki, C. M., Sauer, E. M., Saules, K. K., . . . Wise, E. H. (2014). Introducing the association of psychology training clinics' collaborative research network: A study on client expectancies. Training and Education in Professional Psychology, 8, 95-104. doi:10.1037/tep0000047

*Callahan, J. L., \& Hynan, M. T. (2005). Models of psychotherapy outcome: Are they applicable in training clinics? Psychological Services, 2, 65-69. doi:10.1037/1541-1559.2.1.65 
*Callahan, J. L., Swift, J. K., \& Hynan, M. T. (2006). Test of the phase model of psychotherapy in a training clinic. Psychological Services, 3, 129-136. doi:10.1037/1541-1559.3.2.129

*Capps, K. L., Fiori, K., Mullin, A. S. J., \& Hilsenroth, M. J. (2015). Patient crying in psychotherapy: Who cries and why? Clinical Psychology \& Psychotherapy, 22(3), 208220. doi:10.1002/cpp.1879

*Caspar, F., Berger, T., \& Hautle, I. (2004). The right view of your patient: A computer-assisted individualized module for psychotherapy training. Psychotherapy: Theory, Research, Practice, Training, 41, 125-135. doi:10.1037/0033-3204.41.2.125

*Cellucci, T., Remsperger, P., \& McGlade, E. (2007). Psycho-educational evaluations for university students in one clinic. Psychological Reports, 101, 501-511. doi:10.2466/pr0.101.2.501-511

*Charnas, J. W., Hilsenroth, M. J., Zodan, J., \& Blais, M. A. (2010). Should I stay or should I go? Personality assessment inventory and Rorschach indices of early withdrawal from psychotherapy. Psychotherapy: Theory, Research, Practice, Training, 47, 484-499. doi:10.1037/a0021180

*Chenail, R., Somers, C., \& Benjamin, J. D. (2009). A recursive frame qualitative analysis of MFT progress note tipping points. Contemporary Family Therapy: An International Journal, 31, 87-99. doi:10.1007/s10591-009-9085-7

*Chorpita, B. F., Moffitt, C. E., \& Gray, J. (2005). Psychometric properties of the Revised Child Anxiety and Depression Scale in a clinical sample. Behaviour Research and Therapy, 43, 309-322. doi:10.1016/j.brat.2004.02.004 
Chow, D. L., Miller, S. D., Seidel, J. A., Kane, R. T., Thornton, J. A., \& Andrews, W. P. (2015). The role of deliberate practice in the development of highly effective psychotherapists. Psychotherapy, 52, 337-345. doi:10.1037/pst0000015

*Christenson, J. D. (2008). The relationship of marital and family therapy in a university based training clinic to health care services use. (Doctor of Philosophy), Brigham Young University. Available from Ovid Technologies Dissertation Abstracts International: Section B: The Sciences and Engineering database.

*Chu, B. C., Skriner, L. C., \& Zandberg, L. J. (2013). Shape of change in cognitive behavioural therapy for youth anxiety: Symptom trajectory and predictors of change. Journal of Consulting and Clinical Psychology, 81, 573-587. doi:10.1037/a0033390

*Chu, B. C., Skriner, L. C., \& Zandberg, L. J. (2014). Trajectory and predictors of alliance in cognitive behavioral therapy for youth anxiety. Journal of Clinical Child and Adolescent Psychology, 43, 721-734. doi:10.1080/15374416.2013.785358

*Clark, P., Robertson, J. M., Keen, R., \& Cole, C. (2011). Outcomes of client transfers in a training setting. The American Journal of Family Therapy, 39(3), 214-225. doi:10.1080/01926187.2010.531650

*Conduit, T., Byrne, S., Court, J., \& Stefanovic, S. (2004). Non-attendance at a university-based psychology clinic: Telephone appointment reminders versus no remindes. Australian Psychologist, 39, 68-75. doi:10.1080/00050060410001660362

*Connor, D. R., \& Callahan, J. L. (2015). Impact of psychotherapist expectations on client outcomes. Psychotherapy, 52, 351-362. doi:10.1037/a0038890 
*Constantine, M. G. (2001). Predictors of observer ratings of multicultural counseling competence in black, latino, and white American trainees. Journal of Counseling Psychology, 48, 456-462. doi:10.1037//0022-0167.48.4.456

*Constantino, M. J., Penek, S., Bernecker, S. L., \& Overtree, C. E. (2014). A preliminary examination of participant characteristics in relation to patients' treatment beliefs in psychotherapy in a training clinic. Journal of Psychotherapy Integration, 24, 238-250. doi:10.1037/a0031424

*Constantino, M. J., Schwaiger, E. M., Smith, J. Z., De George, J., McBride, C., Ravitz, P., \& Zuroff, D. C. (2010). Patient interpersonal impacts and the early therapeutic alliance in interpersonal therapy for depression. Psychotherapy: Theory, Research, Practice, Training, 47, 418-424. doi:10.1037/a0021169

*Crafti, N. A. (2002). Integrating cognitive-behavioural and interpersonal approaches in a group program for the eating disorders: Measuring effectiveness in a naturalistic setting. Behaviour Change, 19, 22-38. doi:10.1375/bech.19.1.22

*Cukrowicz, K. C., Timmons, K. A., Sawyer, K., Caron, K. M., Gummelt, H. D., \& Joiner, T. E., Jr. (2011). Improved treatment outcome associated with the shift to empirically supported treatments in an outpatient clinic is maintained over a ten-year period. Professional Psychology: Research and Practice, 42, 145-152. doi:10.1037/a0021937

*Cukrowicz, K. C., White, B. A., Reitzel, L. R., Burns, A. B., Driscoll, K. A., Kemper, T. S., \& Joiner, T. E. (2005). Improved treatment outcome associated with the shift to empirically supported treatments in a graduate training clinic. Professional Psychology: Research and Practice, 36, 330-337. doi:10.1037/0735-7028.36.3.330 
*Dakin, J., \& Wampler, R. (2008). Money doesn't buy happiness, but it helps: Marital satisfaction, psychological distress, and demographic differences between low- and middle-income clinic couples. The American Journal of Family Therapy, 36(4), 300-311. doi:10.1080/01926180701647512

*Deimann, P., \& Kastner-Koller, U. (2011). Maternal evaluations of young children's developmental status: A comparison of clinic- and non-clinic-groups. Psychological Test and Assessment Modeling, 53, 214-227.

*Dennhag, I., \& Armelius, B.-A. (2012). Baseline training in cognitive and psychodynamic psychotherapy during a psychologist training program. Exploring client outcomes in therapies of one or two semesters. Psychotherapy Research, 22, 515-526. doi:10.1080/10503307.2012.677332

*Denton, W. H., Nakonezny, P. A., \& Burwell, S. R. (2010). Reliability and validity of the Global Assessment of Relational Functioning (GARF) in a psychiatric family therapy clinic. Journal of Marital \& Family Therapy, 36, 376-387. doi:10.1111/j.17520606.2009.00144.x

*Diaz, J. P. (1997). Profile analysis of a measure of vigilance and observed behavior in the differential diagnosis of attention deficit hyperactivity disorder in a clinic-referred population. (Doctor of Philosophy), Ball State University. Available from Ovid Technologies Dissertation Abstracts International: Section B: The Sciences and Engineering database.

*Dolan, C. M. (2011). Assessing treatment outcomes by clinical diagnosis in a training clinic. (Master of Science in Clinical Psychology), Pacific University, Hillsboro, Oregon. 
*Doll, B. (1993). Evaluating parental concerns about children's friendships. Journal of School Psychology, 31, 431-447. doi:10.1016/0022-4405(93)90030-M

*Driscoll, K. A., Cukrowicz, K. C., Reitzel, L. R., Hernandez, A., Petty, S. C., \& Joiner, T. E., Jr. (2003). The effect of trainee experience in psychotherapy on client treatment outcome. Behavior Therapy, 34, 165-177. doi:10.1016/S0005-7894(03)80011-4

*Dunkle, J. H., \& Friedlander, M. L. (1996). Contribution of therapist experience and personal characteristics to the working alliance. Journal of Counseling Psychology, 43, 456-460.

*Dunstan, D. A., \& Tooth, S. M. (2012). Treatment via videoconferencing: A pilot study of delivery by clinical psychology trainees. Australian Journal of Rural Health, 20, 88-94. doi:10.1111/j.1440-1584.2012.01260.x

*Elliott, K. P., Westmacott, R., Hunsley, J., Rumstein-McKean, O., \& Best, M. (2015). The process of seeking psychotherapy and its impact on therapy expectations and experiences. Clinical Psychology \& Psychotherapy, 22(5), 399-408. doi:10.1002/cpp.1900

*Ellis, M. V. (2006). Critical incidents in clinical supervision and in supervisor supervision: Assessing supervisory issues. Training and Education in Professional Psychology, S(2), 122-132. doi:10.1037/1931-3918.S.2.122

*Ennis, B. (1999). Differences between ethnic groups in a graduate school psychological service center: Focus of treatment, treatment modality, and termination. (Doctor of Psychology), California School of Professional Psychology. Available from Ovid Technologies Dissertation Abstracts International: Section B: The Sciences and Engineering database.

*Erdodi, L. A., Lajiness-O'Neill, R., \& Saules, K. K. (2010). Order of Conners' CPT-II administration within a cognitive test battery influences ADHD indices. Journal of Attention Disorders, 14, 43-51. doi:10.1177/1087054709347199 
*Erickson, S. A. (2004). The effects of birth order and parent marital status on the development of psychological symptoms. (Doctor of Philosophy), St. John's University. Available from Ovid Technologies Dissertation Abstracts International: Section B: The Sciences and Engineering database.

*Estrada, A. U., \& Russell, R. L. (1999). The development of the Child Psychotherapy Process Scales (CPPS). Psychotherapy Research, 9, 154-166. doi:10.1093/ptr/9.2.154

*Everson, D. (1998). Prediction of treatment attrition in a psychological training clinic using the Personality Assessment Inventory, client variables, and therapist variables. (Doctor of Psychology), Rutgers University. Available from Ovid Technologies Dissertation Abstracts International: Section B: The Sciences and Engineering database.

*Farrell, A. D. (1999a). Development and evaluation of problem frequency scales from Version 3 of the Computerized Assessment System for Psychotherapy Evaluation and Research (CASPER). Journal of Clinical Psychology, 55, 447-464. doi:10.1002/(SICI)10974679(199904)55:4<447::AID-JCLP9>3.0.CO;2-\#

*Farrell, A. D. (1999b). Evaluation of the Computerized Assessment System for Psychotherapy Evaluation and Research (CASPER) as a measure of treatment effectiveness in an outpatient training clinic. Psychological Assessment, 11, 345-358. doi:10.1037/10403590.11.3.345

*Fitzpatrick, M. R., Iwakabe, S., \& Stalikas, A. (2005). Perspective divergence in the working alliance. Psychotherapy Research, 15(1-2), 69-79. doi:10.1080/10503300512331327056

*Fleming, L. M., Glass, J. A., Fujisaki, S., \& Toner, S. L. (2010). Group process and learning: A grounded theory model of group supervision. Training and Education in Professional Psychology, 4, 194-203. doi:10.1037/a0018970 
*Forand, N. R., Evans, S., Haglin, D., \& Fishman, B. (2011). Cognitive behavior therapy in practice: Treatment delivered by trainees at an outpatient clinic is clinically effective. Behavior Therapy, 42, 612-623.

*Forman, E. M., Chapman, J. E., Herbert, J. D., Goetter, E. M., Yuen, E. K., \& Moitra, E. (2012). Using session-by-session measurement to compare mechanisms of action for acceptance and commitment therapy and cognitive therapy. Behavior Therapy, 43, 341-354. doi:10.1016/j.beth.2011.07.004

*Franklin, M. E., Abramowitz, J. S., Furr, J. M., Kalsy, S., \& Riggs, D. S. (2003). A naturalistic examination of therapist experience and outcome of exposure and ritual prevention for OCD. Psychotherapy Research, 13, 153-167. doi:10.1080/713869637

*Frey, L. L., Beesley, D., \& Liang, Y.-S. (2009). The Client Evaluation of Counseling Inventory: Initial validation of an instrument measuring counseling effectiveness. Training and Education in Professional Psychology, 3, 28-36. doi:10.1037/a0012439

*Funderburk, J. S., \& Fielder, R. L. (2013). A primary mental health care model for advanced practicum training in a university health clinic. Training and Education in Professional Psychology, 7, 112-122. doi:10.1037/a0032022

*Gangamma, R., Bartle-Haring, S., Holowacz, E., Hartwell, E. E., \& Glebova, T. (2015). Relational ethics, depressive symptoms, and relationship satisfaction in couples in therapy. Journal of Marital \& Family Therapy, 41(3), 354-366. doi:10.1111/jmft.12070

*Ganske, K. H., Gnilka, P. B., Ashby, J. S., \& Rice, K. G. (2015). The relationship between counseling trainee perfectionism and the working alliance with supervisor and client. Journal of Counseling and Development, 93, 14-24. doi:10.1002/j.15566676.2015.00177.x 
Gard, G., Tremblay, G., DiLillo, D., \& Pantesco, V. (2002). Facilitating research in training clinics: Aspiring to the scientist-practitioner ideal. The Behavior Therapist, 25, 103-106.

*Gelso, C. J., Latts, M. G., Gomez, M. J., \& Fassinger, R. E. (2002). Countertransference management and therapy outcome: An initial evaluation. Journal of Clinical Psychology, 58, 861-867. doi:10.1002/jclp.2010

*George, S. T. (2008). The effect of therapeutic alliance on client dropout: Hierarchical modeling of client feedback. (Doctor of Philosophy), St. Mary's University. Available from Ovid Technologies Dissertation Abstracts International: Section B: The Sciences and Engineering database.

*Germani, G. (2002). Supervisor and trainee perspectives on clinical report writing as narrative. (Doctor of Philosophy), University of Massachusetts Amherst. Available from Ovid Technologies Dissertation Abstracts International: Section B: The Sciences and Engineering database.

*Gold, S. H., Hilsenroth, M. J., Kuutmann, K., \& Owen, J. J. (2015). Therapeutic alliance in the personal therapy of graduate clinicians: Relationship to the alliance and outcomes of their patients. Clinical Psychology \& Psychotherapy, 22(4), 304-316. doi:10.1002/cpp.1888

*Gonsalves, C. J., Hyde, J., Lancaster, S., \& Barrington, J. (2008). University psychology clinics in Australia: Their place in professional training. Australian Psychologist, 43, 278-285. doi:10.1080/00050060802413529

*Goode-Cross, D. T. (2011). "Those who learn have a responsibility to teach": Black therapists' experiences supervising black therapist trainees. Training and Education in Professional Psychology, 5, 73-80. doi:10.1037/a0023187 
*Gray, M. J., Hassija, C. M., Jaconis, M., Barrett, C., Zheng, P., Steinmetz, S., \& James, T. (2015). Provision of evidence-based therapies to rural survivors of domestic violence and sexual assault via telehealth: Treatment outcomes and clinical training benefits. Training and Education in Professional Psychology, 9, 235-241. doi:10.1037/tep0000083

*Greenfield, M. F., Gunthert, K. C., \& Haaga, D. A. (2011). Sudden gains versus gradual gains in a psychotherapy training clinic. Journal of Clinical Psychology, 67, 17-30. doi:10.1002/jclp.20748

*Greenfield, M. F., \& Haaga, D. A. (2011). Accuracy and confidence of training therapists' recognition of sessions before sudden gains. Journal of Cognitive and Behavioral Psychotherapies, 11, 157-172.

*Greenfield, T. M. (2008). Utility of the Symptom Checklist-90-R for predicting unilateral termination at an urban psychology training clinic. (Doctor of Psychology), The Wright Institute. Available from Ovid Technologies Dissertation Abstracts International: Section B: The Sciences and Engineering database.

*Grosse Holtforth, M., \& Grawe, K. (2002). Bern Inventory of Treatment Goals: Part 1. Development and first application of a taxonomy of treatment goal themes. Psychotherapy Research, 12(1), 79-99. doi:10.1093/ptr/12.1.79

*Grossl, A. B., Reese, R. J., Norsworthy, L. A., \& Hopkins, N. B. (2014). Client feedback data in supervision: Effects on supervision and outcome. Training and Education in Professional Psychology, 8, 182-188. doi:10.1037/tep0000025

*Haggerty, G., Hilsenroth, M. J., \& Vala-Stewart, R. (2009). Attachment and interpersonal distress: examining the relationship between attachment styles and interpersonal problems 
in a clinical population. Clinical Psychology \& Psychotherapy, 16(1), 1-9. doi:10.1002/cpp.596

Hansen, N. B., Lambert, M. J., \& Forman, E. M. (2002). The psychotherapy dose-response effect and its implications for treatment delivery services. Clinical Psychology: Science and Practice, 9, 329-343. doi:10.1093/clipsy.9.3.329

*Harnett, P., O'Donovan, A., \& Lambert, M. J. (2010). The dose response relationship in psychotherapy: Implications for social policy. Clinical Psychologist, 14, 39-44. doi:10.1080/13284207.2010.500309

*Hartford, A. J. (1997). An evaluation of university-based psychology practica and training clinic. (Doctor of Psychology), Rutgers University. Available from Ovid Technologies Dissertation Abstracts International Section A: Humanities and Social Sciences database.

*Hatcher, R. L., Wise, E. H., \& Grus, C. L. (2015). Preparation for practicum in professional psychology: A survey of training directors. Training and Education in Professional Psychology, 9, 5-12. doi:10.1037/tep0000060

*Hauch, M. (1998). The Hamburg Model: Couples therapy at century's end. Journal of Sex Education \& Therapy, 23, 237-245. doi:10.1080/01614576.1998.11074248

*Hayes, J. A., Owen, J., \& Bieschke, K. J. (2015). Therapist differences in symptom change with racial/ethnic minority clients. Psychotherapy, 52, 308-314. doi:10.1037/a0037957

*Heppner, M. J., Multon, K. D., Gysbers, N. C., Ellis, C. A., \& Zook, C. E. (1998). The relationship of trainee self-efficacy to the process and outcome of career counseling. Journal of Counseling Psychology, 45, 393-402.

*Hill, C. E., Baumann, E., Shafran, N., Gupta, S., Morrison, A., Rojas, A. E., . . Gelso, C. J. (2015). Is training effective? A study of counseling psychology doctoral trainees in a 
psychodynamic/interpersonal training clinic. Journal of Counseling Psychology, 62, 184201. doi:10.1037/cou0000053

*Hill, C. L., \& Ridley, C. R. (2001). Diagnostic decision making: Do counselors delay final judgments? Journal of Counseling \& Development, 79, 98-104. doi:10.1002/j.15566676.2001.tb01948.x

*Hilsenroth, M. J., Ackerman, S. J., Clemence, A. J., Strassle, C. G., \& Handler, L. (2002). Effects of structured clinician training on patient and therapist perspectives of alliance early in psychotherapy. Psychotherapy: Theory, Research, Practice, Training, 39, 309323. doi:10.1037/0033-3204.39.4.309

*Hilsenroth, M. J., Defife, J. A., Blagys, M. D., \& Ackerman, S. J. (2006). Effects of training in short-term psychodynamic psychotherapy: Changes in graduate clinician technique. Psychotherapy Research, 16(3), 293-305. doi:10.1080/10503300500264887

*Hilsenroth, M. J., Kivlighan, D. M., Jr., \& Slavin-Mulford, J. (2015). Structured supervision of graduate clinicians in psychodynamic psychotherapy: Alliance and technique. Journal of Counseling Psychology, 62, 173-183. doi:10.1037/cou0000058

*Hilsenroth, M. J., Menaker, J., Peters, E. J., \& Pincus, A. L. (2007). Assessment of borderline pathology using the Inventory of Interpersonal Problems Circumplex Scales (IIP-C): a comparison of clinical samples. Clinical Psychology \& Psychotherapy, 14(5), 365-376. doi:10.1002/cpp.549

*Hiltunen, A. J., Kocys, E., \& Perrin-Wallqvist, R. (2013). Effectiveness of cognitive behavioral therapy: An evaluation of therapies provided by trainees at a university psychotherapy training center. PsyCh Journal, 2, 101-112. doi:10.1002/pchj.23 
*Hoffman, M. A., Hill, C. E., Holmes, S. E., \& Freitas, G. F. (2005). Supervisor perspective on the process and outcome of giving easy, difficult, or no feedback to supervisees. Journal of Counseling Psychology, 52, 3-13. doi:10.1037/0022-0167.52.1.3

*Hrapczynski, K. M., Epstein, N. B., Werlinich, C. A., \& LaTaillade, J. J. (2011). Changes in negative attributions during couple therapy for abusive behavior: Relations to changes in satisfaction and behavior. Journal of Marital and Family Therapy, 38(S1), 117-132. doi:10.1111/j.1752-0606.2011.00264.x

*Hunsley, J., Aubry, T. D., Verstervelt, C. M., \& Vito, D. (1999). Comparing therapist and client perspectives on reasons for psychotherapy termination. Psychotherapy: Theory, Research, Practice, Training, 36, 380-388. doi:10.1037/h0087802

*Ilagen, G., Vinson, M., Sharp, J. L., Havice, P., \& Ilagen, J. (2014). Trainees versus staff: Exploring counseling outcomes in a college counseling center. Journal of College Student Psychotherapy, 28, 229-240. doi:10.1080/87568225.2014.915172

Jacobson, N. S., \& Truax, P. (1991). Clinical significance: A statistical approach to defining meaningful change in psychotherapy research. Journal of Consulting and Clinical Psychology, 59, 12-19. doi:10.1037/0022-006X.59.1.12

*Johnson, L. A., \& Caldwell, B. E. (2011). Race, Gender, and Therapist Confidence: Effects on Satisfaction With the Therapeutic Relationship in MFT. The American Journal of Family Therapy, 39(4), 307-324. doi:10.1080/01926187.2010.532012

*Jordan, K. (2007). Beginning supervisees' identity. The Clinical Supervisor, 25(1-2), 43-51. doi:10.1300/J001v25n01_04 
*Kadera, S. W., Lambert, M. J., \& Andrews, A. A. (1996). How much therapy is really enough? A session-by-session analysis of the psychotherapy dose-effect relationship. Journal of Psychotherapy Practice and Research, 5, 132-151.

*Kaplan, D. J. (1994). Internalization in psychotherapy supervision. (Doctor of Philosophy), Wright Institute. Available from Ovid Technologies Dissertation Abstracts International: Section B: The Sciences and Engineering database.

*Kapson, H. S., \& Haaga, D. A. (2010). Depression vulnerability moderates the effects of cognitive behavior therapy in a randomiszed controlled trial for smoking cessation. Behavior Therapy, 41, 447-460.

*Keenan-Miller, D., \& Corbett, H. I. (2015). Metasupervision: Can students be safe and effective supervisors? Training and Education in Professional Psychology, 9, 315-321. doi:10.1037/tep0000090

*Kellems, I. S., Hill, C. E., Crook-Lyon, R. E., \& Freitas, G. (2010). Working with clients who have religious/spiritual issues: A survey of university counseling center therapists. Journal of College Student Psychotherapy, 24, 139-155. doi:10.1080/87568220903558745

*Kendall, P. C. (1994). Treating anxiety disorders in children: Results of a randomized clinical trial. Journal of Consulting and Clinical Psychology, 62, 100-110. doi:10.1037/0022006X.62.1.100

*Kendra, M. S., Mohr, J. J., \& Pollard, J. W. (2014). The stigma of having psychological problems: Relations with engagement, working alliance and depression in psychotherapy. Psychotherapy, 51, 563-573. doi:10.1037/a0036586 
*Keys, A. (2012). Global effectiveness of doctoral practicum students in a university training clinic. (Doctor of Psychology), Regent University. Available from Ovid Technologies Dissertation Abstracts International: Section B: The Sciences and Engineering database.

*Kivlighan, D. M., Jr., Patton, M. J., \& Foote, D. (1998). Moderating effects of client attachment on the counselor experience-working alliance relationship. Journal of Counseling Psychology, 45, 274-278.

*Korobkin, S. B., Herron, W. G., \& Ramirez, S. M. (1998). Severity of symptoms of depression and anxiety as predictors of duration of psychotherapy. Psychological Reports, 82, 427433. doi:10.2466/pr0.1998.82.2.427

*Krasner, R. F., Howard, K. I., \& Brown, A. S. (1998). The acquisition of psychotherapeutic skill: An empirical study. Journal of Clinical Psychology, 54, 895-903. doi:10.1002/(SICI)1097-4679(199811)54:7<895::AID-JCLP4>3.0.CO;2-E

Kraus, D. R., Castonguay, L., Boswell, J. F., Nordberg, S. S., \& Hayes, J. A. (2011). Therapist effectiveness: Implications for accountability and patient care. Psychotherapy Research, 21, 267-276. doi:10.1080/10503307.2011.563249

*Kuentzel, J. G., Hetterscheidt, L. A., \& Barnett, D. (2011). Testing intelligently includes double-checking wechsler IQ scores. Journal of Psychoeducational Assessment, 29, 3946. doi:10.1177/0734282910362048

Lambert, M. J. (2017). Implementing routine outcome monitoring (ROM) in clinical practice. Journal of Health Service Psychology, 43, (fall) 55-59.

*Lambert, M. J., Whipple, J. L., Smart, D. W., Vermeersch, D. A., Nielsen, S. L., \& Hawkins, E. J. (2001). The effects of providing therapists with feedback on patient progress during 
psychotherapy: Are outcomes enhanced? Psychotherapy Research, 11, 49-68. doi:10.1080/713663852

*Lambert, M. J., Whipple, J. L., Vermeersch, D. A., Smart, D. W., Hawkins, E. J., Nielsen, S. L., \& Goates, M. (2002). Enhancing psychotherapy outcomes via providing feedback on client progress: A replication. Clinical Psychology and Psychotherapy, 9, 91-103. doi:10.1002/cpp.324

*Lampropoulos, G. K., Schneider, M. K., \& Spengler, P. M. (2009). Predictors of early termination in a university counseling training clinic. Journal of Counseling and Development, 87, 36-46.

*Landry, R. W. (1998). Client-therapist interpersonal variables and premature termination during the early stage of psychotherapy. Pacific Graduate School of Psychology. Available from Ovid Technologies Dissertation Abstracts International: Section B: The Sciences and Engineering database.

*Lappalainen, R., Lehtonen, T., Skarp, E., Taubert, E., Ojanen, M., \& Hayes, S. C. (2007). The impact of CBT and ACT models using psychology trainee therapists: A preliminary controlled effectiveness trial. Behaviour Modification, 31, 488-511. doi:10.1177/0145445506298436

*Lawe, C. F., Penick, J. M., Raskin, J. D., \& Raymond, V. V. (1999). Influences to refer at university counseling centers. Journal of College Student Psychotherapy, 14, 59-68. doi:10.1300/J035v14n01_05

*Lee, R. W., \& Cashwell, C. S. (2002). Ethical issues in counseling supervision. The Clinical Supervisor, 20(2), 91-100. doi:10.1300/J001v20n02_08 
*Leibert, T. W. (2010). Brief client self-report predictors of psychological distress: Implications for counseling outcome studies. Counseling Outcome Research and Evaluation, 1(2), 5067. doi:10.1177/2150137810373612

*Leibert, T. W., \& Dunne-Bryant, A. (2015). Do common factors account for counseling outcome? Journal of Counseling \& Development, 93, 225-235. doi:10.1002/j.15566676.2015.00198.x

*Leibert, T. W., Smith, J. B., \& Agaskar, V. R. (2011). Relationship between the working alliance and social support on counseling outcome. Journal of Clinical Psychology, 67, 709-719. doi:10.1002/jclp.20800

*Lent, R. W., Cinamon, R. G., Bryan, N. A., Jezzi, M. M., Martin, H. M., \& Lim, R. (2009). Perceived sources of change in trainees' self-efficacy beliefs. Psychotherapy: Theory, Research, Practice, Training, 46, 317-327. doi:10.1037/a0017029

*Lester, S., \& Harris, S. M. (2007). Factors associated with first session nonattendance at a university-based family therapy clinic. The American Journal of Family Therapy, 35, 363-376. doi:10.1080/01926180600814718

*Lewis, C. C., Simons, A. D., \& Kim, H. K. (2012). The role of early symptom trajectories and pretreatment variables in predicting treatment response to cognitive behavioral therapy. Journal of Consulting and Clinical Psychology, 80, 525-534. doi:10.1037/a0029131

*Lewis, S. L. (2007). The relationship between anxiety and premature termination from psychotherapy at a university clinic. (Doctor of Philosophy), The Florida State University. Available from Ovid Technologies Dissertation Abstracts International: Section B: The Sciences and Engineering database. 
*Ligiéro, D. P., \& Gelso, C. J. (2002). Countertransference, attachment, and the working alliance: The therapist's contributions. Psychotherapy: Theory, Research, Practice, Training, 39, 3-11. doi:10.1037//0033-3204.39.1.3

*Locke, L. D., \& McCollum, E. E. (2001). Clients' views of live supervision and satisfaction with therapy. Journal of Marital and Family Therapy, 27, 129-133. doi:10.1111/j.17520606.2001.tb01146.x

*Long, J. R. (2001). Goal agreement and early therapeutic change. Psychotherapy: Theory, Research, Practice, Training, 38, 219-232. doi:10.1037/0033-3204.38.2.219

*Lopez, R. J. (2011). Effect of exposure-based parent-child interaction therapy on early childhood compulsive behaviors. (Doctor of Philosophy), Hofstra University. Available from Ovid Technologies Dissertation Abstracts International: Section B: The Sciences and Engineering database.

*Lucas, M. S. (1993). A validation of types of career indecision at a counseling center. Journal of Counseling Psychology, 40, 440-446.

*Lucas, M. S. (2012). Counseling on campus: Client persistence and progress. Journal of College Student Psychotherapy, 26(3), 227-240. doi:10.1080/87568225.2012.685856

Lutz, W., Leon, S. C., Martinovich, Z., Lyons, J. S., \& Stiles, W. B. (2007). Therapist effects in outpatient psychotherapy: A three-level growth curve approach. Journal of Counseling Psychology, 54, 32-39. doi:10.1037/0022-0167.54.1.32

*Magyar-Moe, J. L., Pedrotti, J. T., Edwards, L. M., Ford, A. I., Petersen, S. E., Rasmussen, H. N., \& Ryder, J. A. (2005). Perceptions of multicultural training in predoctoral internship programs: A survey of interns and training directors. Professional Psychology - Research \& Practice, 36, 446-450. doi:10.1037/0735-7028.36.4.446 
*Mallinckrodt, B. (1993). Session impact, working alliance, and treatment outcome in brief counseling. Journal of Counseling Psychology, 40, 25-32. doi:10.1037/0022-0167.40.1.25

*Marmarosh, C. L., Gelso, C. J., Markin, R. D., Majors, R., Mallery, C., \& Choi, J. (2009). The real relationship in psychotherapy: Relationships to adult attachments, working alliance, transference, and therapy outcome. Journal of Counseling Psychology, 56, 337-350. doi:10.1037/a0015169

*Marmarosh, C. L., Kivlighan, D. M., Jr., Bieri, K., LaFauci Schutt, J. M., Barone, C., \& Choi, J. (2014). The insecure psychotherapy base: Using client and therapist attachment styles to understand the early alliance. Psychotherapy, 51, 404-412. doi:10.1037/a0031989

*Marmarosh, C. L., Nikityn, M., Moehringer, J., Ferraioli, L., Kahn, S., Cerkevich, A., . . . Reisch, E. (2013). Adult attachment, attachment to the supervisor, and the supervisory alliance: How they relate to novice therapists' perceived counseling self-efficacy. Psychotherapy, 50, 178-188. doi:10.1037/a0033028

*Marmarosh, C. L., Schmidt, E., Pembleton, J., Rotbart, E., Muzyk, N., Liner, A., . . Salmen, K. (2015). Novice therapist attachment and perceived ruptures and repairs: A pilot study. Psychotherapy, 52, 140-144. doi:10.1037/a0036129

McAleavey, A. A., Lockard, A. J., Castonguay, L. G., Hayes, J. A., \& Locke, B. D. (2015). Building a practice research network: Obstacles faced and lessons learned at the Center for Collegiate Mental Health. Psychotherapy Research, 25, 134-151. doi:10.1080/10503307.2014.883652

*McClintock, A. S., Anderson, T., \& Petrarca, A. (2015). Treatment expectations, alliance, session positivity, and outcome: An investigation of a three-path mediation model. Journal of Clinical Psychology, 71, 41-49. doi:10.1002/jclp.22119 
*Merrin, J. B. (2007). Performance measurement outcomes of clinical services at a communitybased behavioral health training clinic. (Doctor of Philosophy), Alliant International University. Available from Ovid Technologies Dissertation Abstracts International: Section B: The Sciences and Engineering database.

*Michael, K. D., Furr, R., Masters, K. S., Collett, B. R., Spielmans, G. I., Ritter, K., .. . Cullum, J. L. (2009). Using the MMPI-2 to predict symptom reduction during psychotherapy in a sample of community outpatients. Journal of Contemporary Psychotherapy, 39, 157-163. doi:10.1007/s10879-008-9109-x

Miller, S. D., Hubble, M. A., Chow, D. L., \& Seidel, J. A. (2013). The outcome of psychotherapy: Yesterday, today and tomorrow. Psychotherapy, 50, 88-97. doi:10.1037/a0031097

*Minami, T., Davies, D. R., Tierney, S. C., Bettmann, J. E., McAward, S. M., Averill, L. A., .. . Wampold, B. E. (2009). Preliminary evidence on the effectiveness of psychological treatments delivered at a university counseling center. Journal of Counseling Psychology, 56, 309-320. doi:10.1037/a0015398

*Mitchell, J. L. (2008). The relationship between interpersonal dependency and therapeutic alliance: Perspectives of clients and therapists. (Doctor of Philosophy), University of North Texas. Available from Ovid Technologies Dissertation Abstracts International: Section B: The Sciences and Engineering database.

*Moore, K. E., \& Kenning, M. (1996). Assessing client satisfaction in a psychology training clinic. Journal of Mental Health Administration, 23, 180-189. doi:10.1007/BF02519109

*Moynehan, J., \& Adams, J. (2007). What's the problem? A look at men in marital therapy. The American Journal of Family Therapy, 35(1), 41-51. doi:10.1080/01926180600553381 
*Mueller, B. W. (2010). An exploratory study of the creation of a group psychotherapy training clinic. (Doctor of Psychology), Rutgers University. Available from Ovid Technologies Dissertation Abstracts International: Section B: The Sciences and Engineering database.

*Murrell, E., Steel, Z., Gaston, J., \& Proudfoot, H. (2002). Training the clinical psychologist: Profile of a university-based clinic. Australian Psychologist, 37, 123-128. doi:10.1080/00050060210001706766

*Nathan, V., \& Poulson, S. (2004). Group-analytic training groups for psychology students: A qualitative study. Group Analysis, 37, 163-177. doi:10.1177/0533316404042855

Neufeldt, S. A., \& Nelson, M. L. (1998). Research in training clinics: A bridge between science and practice. Journal of Clinical Psychology, 54, 315-327. doi:10.1002/(SICI)10974679(199804)54:3<315::AID-JCLP3>3.0.CO;2-O

*Nichols, S. (2009). The process of internalization in psychotherapy and its relationship to the working alliance and therapeutic change. (Doctor of Philosophy), Long Island University. Available from Ovid Technologies Dissertation Abstracts International: Section B: The Sciences and Engineering database.

*Niemeyer, K. M. (2004). An exploration of object relations and the early working alliance in a university clinic sample. (Doctor of Philosophy), University of North Texas. Available from Ovid Technologies Dissertation Abstracts International: Section B: The Sciences and Engineering database.

*Nilsson, J. E., Schale, C. L., \& Khamphakdy-Brown, S. (2011). Facilitating trainees' multicultural development and social justice advocacy through a refugee/immigrant mental health program. Journal of Counseling \& Development, 89, 413-422. doi:10.1002/j.1556-6676.2011.tb02838.x 
*Nutt-Williams, E., \& Hill, C. E. (1996). The relationship between self-talk and therapy process variable for novice therapists. Journal of Counseling Psychology, 43, 170-177.

*Nyman, S. J., Nafziger, M. A., \& Smith, T. B. (2010). Client outcomes across counselor training level within a multitiered supervision model. Journal of Counseling and Development, 88, 204-209. doi:10.1002/j.1556-6678.2010.tb00010.x

*O'Brien, D., McCallin, A., \& Bassett, S. (2013). Student perceptions of an interprofessional clinical experience at a university clinic. New Zealand Journal of Physiotherapy, 41, 8187.

*Ögren, M.-L., Jonsson, C.-O., \& Sundin, E. C. (2005). Group supervision in psychotherapy: The relationship between focus, group climate, and perceived attained skill. Journal of Clinical Psychology, 61, 373-388. doi:10.1002/jclp.20056

*Ögren, M.-L., \& Sundin, E. C. (2007). Experiences of the group format in psychotherapy supervision. The Clinical Supervisor, 25(1-2), 69-82. doi:10.1300/ J001v25n01_06

Okiishi, J. C., Lambert, M. J., Eggett, D., Nielsen, L., Dayton, D. D., \& Vermeersch, D. A. (2006). An analysis of therapist treatment effects: Toward providing feedback to individual therapists on their clients' psychotherapy outcome. Journal of Clinical Psychology, 62, 1157-1172. doi:10.1002/jclp.20272

*Öst, L. G., Karlstedt, A., \& Widén, S. (2012). The effects of cognitive behavior therapy delivered by students in a psychologist training program: An effectiveness study. Behavior Therapy, 43, 160-173.

*Owen, J., \& Hilsenroth, M. J. (2014). Treatment adherence: The importance of therapist flexibility in relation to therapy outcomes. Journal of Counseling Psychology, 61, 280288. doi:10.1037/a0035753 
*Owen, J., Keller, B., Shuck, B., Luebcke, B., Knopp, K., \& Rhoades, G. K. (2014). An initial examination of commitment uncertainty in couple therapy. Couple and Family Psychology: Research and Practice, 3, 232-238. doi:10.1037/cfp0000030

*Pachana, N. A., O'Donovan, A., \& Helmes, E. (2006). Australian clinical psychology training program directors survey. Australian Psychologist, 41, 168-178. doi:10.1080/00050060600820644

*Pakenham, K. I. (2015). Investigation of the utility of the acceptance and commitment therapy (ACT) framework for fostering self-care in clinical psychology trainees. Training and Education in Professional Psychology, 9, 144-152. doi:10.1037/tep0000074

*Parker-Sloat, E. L. (2003). Client-therapist ethnicity and gender matching as predictors of length of treatment and goal completion at a practicum training clinic. (Doctor of Philosophy), University of Miami. Available from Ovid Technologies Dissertation Abstracts International: Section B: The Sciences and Engineering database.

*Patterson, C. L., Anderson, T., \& Wei, C. (2014). Clients' pretreatment role expectations, the therapeutic alliance, and clinical outcomes in outpatient therapy. Journal of Clinical Psychology, 70, 673-680. doi:10.1002/jclp.22054

*Pesale, F. P., \& Hilsenroth, M. J. (2009). Patient and therapist perspectives on session depth in relation to technique during psychodynamic psychotherapy. Psychotherapy: Theory, Research, Practice, Training, 46, 390-396. doi:10.1037/a0016999

*Pesale, F. P., Hilsenroth, M. J., \& Owen, J. J. (2012). Patient early session experience and treatment outcome. Psychotherapy Research, 22(4), 417-425. doi:10.1080/10503307.2012.662607 
Pickering, C., \& Byrne, J. (2014). The benefits of publishing systematic quantitative literature reviews for $\mathrm{PhD}$ candidates and other early-career researchers. Higher Education Research and Development, 33, 534-548. doi:10.1080/07294360.2013.841651

*Pinto, A. (2002). Effect of treatment recommendation format on parental satisfaction and compliance. (Doctor of Philosophy), Hofstra University. Available from Ovid Technologies Dissertation Abstracts International: Section B: The Sciences and Engineering database.

*Poulsen, S., Lunn, S., \& Sandros, C. (2010). Client experience of psychodynamic psychotherapy for bulimia nervosa: an interview study. Psychotherapy: Theory, Research, Practice, Training, 47, 469-483. doi:10.1037/a0021178

*Powell, J. L., Hunter, H. L., Beasley, L. O., \& Vernberg, E. M. (2010). Using fine-grained indexes of therapists' experience and training to predict treatment outcomes in a university-based training clinic for children and families. Training and Education in Professional Psychology, 4, 138-144. doi:10.1037/a0018369

*Principe, B. A. (2001). Parents' implicit beliefs and the motivational response patterns of children with a history of reading failure. (Doctor of Philosophy), Columbia University. Available from Ovid Technologies Dissertation Abstracts International: Section B: The Sciences and Engineering database.

*Quick, K. A. (1997). An evaluation of a brief IQ test for school use. (Doctor of Philosophy), Hofstra University. Available from Ovid Technologies PsycINFO database.

*Reese, R. J., Norsworthy, L. A., \& Rowlands, S. R. (2009). Does a continuous feedback system improve psychotherapy outcome? Psychotherapy: Theory, Research, Practice, Training, 46, 418-431. doi:10.1037/a0017901 
*Reese, R. J., Toland, M. D., \& Hopkins, N. B. (2011). Replicating and extending the goodenough level model of change: Considering session frequency. Psychotherapy Research, 21, 608-619. doi:10.1080/10503307.2011.598580

*Reese, R. J., Usher, E. L., Bowman, D. C., Norsworthy, L. A., Halstead, J. L., Rowlands, S. R., \& Chisholm, R. R. (2009). Using client feedback in psychotherapy training: An analysis of its influence on supervision and counselor self-efficacy. Training and Education in Professional Psychology, 3, 157-168.

*Renk, K., \& Dinger, T. M. (2002). Reasons for therapy termination in a university psychology clinic. Journal of Clinical Psychology, 58, 1173-1181. doi:10.1002/jclp.10075

*Renk, K., Dinger, T. M., \& Bjugstad, K. (2000). Predicting therapy duration from therapist experience and client psychopathology. Journal of Clinical Psychology, 56, 1609-1614. doi:10.1002/1097-4679(200012)56:12<1609::AID-11>3.0.CO;2-U

*Reynolds, D. A. J., Jr., \& Stiles, W. B. (2007). Online data collection for psychotherapy process research. CyberPsychology \& Behavior, 10(1), 92-99. doi:10.1089/cpb.2006.9987

*Rice, K. G., Sauer, E. M., Richardson, C. M., Roberts, K. E., \& Garrison, A. M. (2015). Perfectionism affects change in psychological symptoms. Psychotherapy, 52, 218-227. doi:10.1037/a0036507

*Ricker, M., Nystul, M., \& Waldo, M. (1999). Counselors' and clients' ethnic similarity and therapeutic alliance in time-limited outcomes of counseling. Psychological Reports, 84, 674-676. doi:10.2466/pr0.1999.84.2.674

*Rieck, T., \& Callahan, J. L. (2013). Emotional intelligence and psychotherapy outcomes in the training clinic. Training and Education in Professional Psychology, 7, 42-52. doi:10.1037/a0031659 
*Rieck, T., Callahan, J. L., \& Watkins, C. (2015). Clinical supervision: An exploration of possible mechanisms of action. Training and Education in Professional Psychology, 9, 187-194. doi:10.1037/tep0000080

*Romano, V., Janzen, J. I., \& Fitzpatrick, M. R. (2009). Volunteer client attachment moderates the relationship between trainee therapist attachment and therapist interventions. Psychotherapy Research, 19, 666-676. doi:10.1080/10503300902926547

*Romans, J. S. C. (1996). Gender differences in counselor/therapist trainees. The Clinical Supervisor, 14(1), 77-85. doi:10.1300/J001v14n01_06

*Rosen, K. H., McCollum, E. E., Middleton, K., Locke, L., \& Bird, K. (1997). Interrater reliability and validity of the global assessment of relational functioning scale in a clinical setting: A preliminary study. The American Journal of Family Therapy, 25(4), 357-360. doi:10.1080/01926189708251079

*Ryan, E. J. (2007). Children's verbalizations in psychotherapy. (Doctor of Philosophy), St John's University. Available from Ovid Technologies Dissertation Abstracts International: Section B: The Sciences and Engineering database.

*Ryum, T., Vogel, P. A., Walderhaug, E. P., \& Stiles, T. C. (2015). The role of self-image as a predictor of psychotherapy outcome. Scandinavian Journal of Psychology, 56, 62-68. doi:10.1111/sjop.12167

*Sadock, E., Auerbach, S. M., Rybarczyk, B., \& Aggarwal, A. (2014). Evaluation of integrated psychological services in a university-based primary care clinic. Journal of Clinical Psychology in Medical Settings, 21, 19-32. doi:10.1007/s10880-013-9378-8 
*Sandberg, J. G., Feldhousen, E. B., \& Busby, D. M. (2012). The impact of childhood abuse on women's and men's perceived parenting: Implications for practitioners. The American Journal of Family Therapy, 40, 74-91. doi:10.1080/01926187.2011.566827

*Sanders Thompson, V. L., \& Alexander, H. (2006). Therapists' race and African American clients' reactions to therapy. Psychotherapy: Theory, Research, Practice, Training, 43, 99-110. doi:10.1037/0033-3204.43.1.99

*Satterfield, W. A., Buelow, S. A., Lyddon, W. J., \& Johnson, J. T. (1995). Client stages of change and expectations about counseling. Journal of Counseling Psychology, 42, 476478. doi:10.1037/0022-0167.42.4.476

*Satterfield, W. A., \& Lyddon, W. J. (1995). Client attachment and perceptions of the working alliance with counselor trainees. Journal of Counseling Psychology, 42, 187-189.

Sauer, E. M. (2006). Living the scientist-practitioner model in a psychology training clinic. Counselling Psychology Quarterly, 19, 293-304. doi:10.1080/09515070600960498

*Sauer, E. M., Anderson, M. Z., Gormley, B., Richmond, C. J., \& Preacco, L. (2010). Client attachment orientations, working alliances, and responses to therapy: A psychology training clinic study. Psychotherapy Research, 20, 702-711. doi:10.1080/10503307.2010.518635

Sauer, E. M., \& Huber, D. M. (2007). Implementing the Boulder model of training in a psychology training clinic. Journal of Contemporary Psychotherapy, 37, 221-228. doi:10.1007/s10879-007-9057-X

*Schomaker, S. A., \& Ricard, R. J. (2015). Effect of a mindfulness-based intervention on counselor-client attunement. Journal of Counseling \& Development, 93, 491-498. doi:10.1002/jcad.12047 
*Schottke, H., Trame, L., \& Sembill, A. (2014). Relevance of therapy goals in outpatient cognitive-behavioral and psychodynamic psychotherapy. Psychotherapy Research, 24, 711-723. doi:10.1080/10503307.2014.881578

*Seigers, D. K. L., \& Carey, K. B. (2010). Alcohol use, psychopathology and treatment utilization in a university mental health clinic. Journal of College Student Psychotherapy, 24(4), 328-337. doi:10.1080/87568225.2010.509250

*Sells, S. P., Smith, T. E., \& Moon, S. (1996). An ethnographic study of client and therapist perceptions of therapy effectiveness in a university-based training clinic. Journal of Marital and Family Therapy, 22, 321-342. doi:10.1111/j.1752-0606.1996.tb00209.x

*Siefert, C. J., Hilsenroth, M. J., Weinberger, J., Blagys, M. D., \& Ackerman, S. J. (2006). The relationship of patient defensive functioning and alliance with therapist technique during short-term psychodynamic psychotherapy. Clinical Psychology \& Psychotherapy, 13(1), 20-33. doi:10.1002/cpp.469

*Simpson, S., Guerrini, L., \& Rochford, S. (2015). Telepsychology in a university psychology clinic setting: A pilot project. Australian Psychologist, 50, 285-291. doi:10.1111/ap.12131

*Snell, M. N., Mallinckrodt, B., Hill, R. D., \& Lambert, M. J. (2001). Predicting counseling center clients' response to counseling: A 1-year follow-up. Journal of Counseling Psychology, 48, 463-473. doi:10.1037//0022-0167.48.4.463

*Sobell, L. C., Manor, H. L., Sobell, M. B., \& Dum, M. (2008). Self-critiques of audiotaped therapy sessions: A motivational procedure for facilitating feedback during supervision. Training and Education in Professional Psychology, 2, 151-155. doi:10.1037/19313918.2.3.151 
*Soberay, A., Faragher, J. M., Barbash, M., Brookover, A., \& Grimsley, P. (2014). Pathological gambling, co-occurring disorders, clinical presentation, and treatment outcomes at a university-based counseling clinic. Journal of Gambling Studies, 30, 61-69. doi:10.1007/s10899-012-9357-2

*Southam-Gerow, M. A., Chorpita, B. F., Miller, L. M., \& Gleacher, A. A. (2008). Are children with anxiety disorders privately referred to a university clinic like those referred for the public mental health system? Administration and policy in mental health and mental health services research, 35, 168-180. doi:10.1007/s10488-007-0154-7

*Southam-Gerow, M. A., Kendall, P. C., \& Weersing, R. (2001). Examining outcome variability: Correlates of treatment response in a child and adolescent anxiety clinic. Journal of Clinical Child and Adolescent Psychology, 30, 422-436. doi:10.1207/S15374424JCCP3003_13

*Spence, S. H., Holmes, J. M., March, S., \& Lipp, O. V. (2006). The feasibility and outcome of clinic plus internet delivery of cognitive-behavior therapy for childhood anxiety. Journal of Consulting and Clinical Psychology, 74, 614-621. doi:10.1037/0022-006X.74.3.614

*Spielmans, G. I., Masters, K. S., \& Lambert, M. J. (2006). A comparison of rational versus empirical methods in the prediction of psychotherapy outcome. Clinical Psychology and Psychotherapy, 13, 202-214. doi:10.1002/cpp.491

*Springer-Kremser, M., Eder, A., Jandl-Jager, E., \& Hager, I. (2002). Can legislation provide a better match between demand and supply in psychotherapy? Social Psychiatry and Psychiatric Epidemiology, 37, 492-500. doi:10.1007/s00127-002-0574-3

*Stahl, J. V., Hill, C. E., Jacobs, T., Kleinman, S., Isenberg, D., \& Stern, A. (2009). When the shoe is on the other foot: A qualitative study of intern-level trainees' perceived learning 
from clients. Psychotherapy: Theory, Research, Practice, Training, 46, 376-389. doi:10.1037/a0017000

*Stallman, H. M., Morawska, A., \& Sanders, M. R. (2009). Parent Problem Checklist: Tool for assessing parent conflict. Australian Psychologist, 44(2), 78-85. doi:10.1080/00050060802630023

*Stedman, J. M., Hatch, J. P., \& Schoenfeld, L. S. (2007). Toward practice-oriented theoretical models for internship training. Training and Education in Professional Psychology, 1, 8994. doi:10.1037/1931-3918.1.2.89

*Stein, M. B., Siefert, C. J., Stewart, R. V., \& Hilsenroth, M. J. (2011). Relationship between the Social Cognition and Object Relations Scale (SCORS) and attachment style in a clinical sample. Clinical Psychology \& Psychotherapy, 18(6), 512-523. doi:10.1002/cpp.721

*Strohmer, D. C., Leierer, S. J., Hotard, J. M., \& Stuckey, R. I. (2003). Counselor preferences of clients entering a counselor-training clinic. Rehabilitation Counseling Bulletin, 47, 45-49.

*Stukenberg, K. W., Dacey, C. M., \& Nagy, M. S. (2006). Psychotherapy services provided by a college counseling center: Continuity through change over 37 years. Journal of College Student Psychotherapy, 20(4), 53-70. doi:10.1300/J035v20n04_06

*Sumerel, M. B., \& Borders, L. D. (1995). Supervision of career counseling interns. The Clinical Supervisor, 13(1), 91-100. doi:10.1300/J001v13n01_07

*Swift, J. K., \& Callahan, J. L. (2010). A comparison of client preferences for intervention empirical support versus common therapy variables. Journal of Clinical Psychology, 66, 1217-1231. doi:10.1002/jclp.20720 
*Swift, J. K., \& Callahan, J. L. (2011). Decreasing treatment dropout by addressing expectations for treatment length. Psychotherapy Research, 21, 193-200.

doi:10.1080/10503307.2010.541294

*Swift, J. K., Callahan, J. L., Heath, C. J., Herbert, G. L., \& Levine, J. C. (2010). Applications of the psychotherapy phase model to clinically significant deterioration. Psychotherapy: Theory, Research, Practice, Training, 47, 235-248. doi:10.1037/a0019787

*Swift, J. K., Callahan, J. L., \& Levine, J. C. (2009). Using clinically significant change to identify premature termination. Psychotherapy: Theory, Research, Practice, Training, 46, 328-335. doi:10.1037/a0017003

*Swift, J. K., Whipple, J. L., \& Sandberg, P. (2012). A prediction of initial appointment attendance and initial outcome expectations. Psychotherapy, 49, 549-556. doi:10.1037/a0029441

*Tanner, M. A., Gray, J. J., \& Haaga, D. A. (2012). Association of cotherapy supervision with client outcomes, attrition, and trainee effectiveness in a psychotherapy training clinic. Journal of Clinical Psychology, 68, 1241-1252. doi:10.1002/jclp.21902

*Thomas, M. L. (2012). Rewards of bridging the divide between measurement and clinical theory: demonstration of a bifactor model for the brief symptom inventory. Psychological Assessment, 24, 101-113. doi:10.1037/a0024712

*Thompson, B. J., \& Hill, C. E. (1993). Client perceptions of therapist competence. Psychotherapy Research, 3(2), 124-130. doi:10.1080/1050330931233133729

*Todd, D. M., Deane, F. P., \& Bragdon, R. A. (2003). Client and therapist reasons for termination: A conceptualization and preliminary validation. Journal of Clinical Psychology, 59, 133-147. doi:10.1002/jclp.10123 
*Todd, D. M., Deane, F. P., \& McKenna, P. A. (1997). Appropriateness of SCL-90-R adolescent and adult norms for outpatient and nonpatient college students. Journal of Counseling Psychology, 44, 294-301.

Todd, D. M., Kurcias, J., \& Gloster, K. (1994). Review of research conducted in psychology program training clinics. Professional Psychology: Research and Practice, 25(4), 471481. doi:10.1037/0735-7028.25.4.471

*Tokar, D. M., Hardin, S. I., Adams, E. M., \& Brandel, I. W. (1996). Clients' expectations about counseling and perceptions of the working alliance. Journal of College Student Psychotherapy, 11(2), 9-26. doi:10.1300/J035v11n02_03

*Tracey, T. J. G., Bludworth, J., \& Glidden-Tracey, C. E. (2012). Are there parallel processes in psychotherapy supervision? An empirical examination. Psychotherapy, 49, 330-343. doi:10.1037/a0026246

*Tryon, G. S., \& Kane, A. S. (1993). Relationship of working alliance to mutual and unilateral termination. Journal of Counseling Psychology, 40, 33-36.

*Tsai, M. H., \& Ray, D. C. (2011). Children in therapy: Learning from evaluation of universitybased community counseling clinical services. Children and Youth Services Review, 33, 901-909. doi:10.1016/j.childyouth.2010.12.011

*Van Orden, K. A., Lynam, M. E., Hollar, D., \& Joiner Jr, T. E. (2006). Perceived burdensomeness as an indicator of suicidal symptoms. Cognitive Therapy and Research, 30, 457-467. doi:10.1007/s10608-006-9057-2

*Van Orden, K. A., Witte, T. K., Gordon, K. H., Bender, T. W., \& Joiner, T. E., Jr. (2008). Suicidal desire and the capability for suicide: Tests of the interpersonal-psychological 
theory of suicidal behavior among adults. Journal of Consulting and Clinical Psychology, 78, 72-83. doi:10.1037/0022-006X.76.1.72

*Vega, B. R., Melero-Llorente, J., Perez, C. B., Cebolla, S., Mira, J., Valverde, C., \& FernandezLiria, A. (2014). Impact of mindfulness training on attentional control and anger regulation processes for psychotherapists in training. Psychotherapy Research, 24, 202213. doi:10.1080/10503307.2013.838651

*Vespia, K. M., Heckman-Stone, C., \& Delworth, U. (2002). Describing and facilitating effective supervision behavior in counseling trainees. Psychotherapy: Theory, Research, Practice, Training, 39, 56-65. doi:10.1037//0033-3204.39.1.56

*Ward, D. B., \& McCollum, E. E. (2005). Treatment effectiveness and its correlates in a marriage and family therapy training clinic. The American Journal of Family Therapy, 33, 207-223. doi:10.1080/01926180590932960

*Wark, L. (1995a). Defining the territory of live supervision in family therapy training. The Clinical Supervisor, 13(1), 145-162. doi:10.1300/J001v13n01_11

*Wark, L. (1995b). Live supervision in family therapy: Qualitative interviews of supervision events as perceived by supervisors and supervisees. The American Journal of Family Therapy, 23(1), 25-37. doi:10.1080/01926189508251333

*Warner, L. K., Herron, W. G., Javier, R. A., Patalano, F., Sisenwein, F., \& Primavera, L. H. (2001). A comparison of dose-response curves in cognitive-behavioral and psychodynamic psychotherapies. Journal of Clinical Psychology, 57, 63-73. doi:10.1002/1097-4679(200101)57:1<63::AID-JCLP8>3.0.CO;2-E 
*Watson, N., Bryan, B. C., \& Thrash, T. M. (2010). Self-discrepancy: Comparisons of the psychometric properties of three instruments. Psychological Assessment, 22, 878-892. doi:10.1037/a0020644

*Westmacott, R., Hunsley, J., Best, M., Rumstein-McKean, O., \& Schindler, D. (2010). Client and therapist views of contextual factors related to termination from psychotherapy: A comparison between unilateral and mutual terminators. Psychotherapy Research, 20, 423435. doi:10.1080/10503301003645796

Wheeler, S., \& Richards, K. (2007). The impact of clinical supervision on counsellors and therapists, their practice and their clients. A systematic review of the literature. Counselling and Psychotherapy Research, 7(1), 54-65. doi:10.1080/14733140601185274

*Winkel, J. D. (2006). Exploring the relationship between time series data collection and duration of treatment in a university clinic: A survival analysis. (Doctor of Philosophy), University of Tennessee. Available from Ovid Technologies Dissertation Abstracts International: Section B: The Sciences and Engineering database.

*Wolfe, S. (2011). A comparison of counseling outcomes and perceptions of counselors between Hispanic and Anglo college students. (Doctor of Philosophy), New Mexico State University. Available from Ovid Technologies Dissertation Abstracts International: Section B: The Sciences and Engineering database.

*Wolgast, B. M., Lambert, M. J., \& Puschner, B. (2004). The dose-response relationship at a college counseling center: Implications for setting session limits. Journal of College Student Psychotherapy, 18(2), 15-29. doi:10.1300/J035v18n02_03 
*Wrape, E. R., Callahan, J. L., Ruggero, C. J., \& Watkins, E. C., Jnr. (2015). An exploration of faculty supervisor variables and their impact on client outcomes. Training and Education in Professional Psychology, 9, 35-43. doi:10.1037/tep0000014

*Xu, H., \& Tracey, T. J. (2015). Reciprocal influence model of working alliance and therapeutic outcome over individual therapy course. Journal of Counseling Psychology, 62, 351-359. doi:10.1037/cou0000089

*Young, T. L., Gutierrez, D., \& Hagedorn, W. B. (2013). Does motivational interviewing (MI) work with nonaddicted clients? A controlled study measuring the effects of a brief training in MI on client outcomes. Journal of Counseling \& Development, 91, 313-320. doi:10.1002/j.1556-6676.2013.00099.x

*Zhang, N., \& McCoy, V. A. (2008). Discussion of racial difference in counseling: A counselor's perspective. Journal of College Student Psychotherapy, 23, 3-15. doi:10.1080/87568220802367479

*Zimmerman, J., \& Bambling, M. (2012). Influence of therapist variables on working alliance and therapy outcome. Psychotherapy in Australia, 18, 76-82.

*Zuckerman, A., \& Mitchell, C. L. (2004). Psychology interns' perspectives on the forced termination of psychotherapy. The Clinical Supervisor, 23(1), 55-70. doi:10.1300/J001v23n01_04 
Table 1

The main aim(s) of each study included in the review by number of USA and non-USA studies

\begin{tabular}{|c|c|c|c|}
\hline \multirow{2}{*}{ Aim: Topic of Research } & \multicolumn{3}{|c|}{ Number of Studies } \\
\hline & USA & Non-USA & Total \\
\hline Nature and Organisation of Training Clinics & & & 52 \\
\hline Program Evaluation & 9 & 5 & 14 \\
\hline Description of Service Delivery & 6 & 6 & 12 \\
\hline Policy and Procedures & 6 & 4 & 10 \\
\hline Clinic Demographics (description of clinic clients) & 7 & 2 & 9 \\
\hline Access to Care & 3 & 3 & 6 \\
\hline Continuity of Care & 1 & 0 & 1 \\
\hline Client Characteristics & & & 48 \\
\hline Client Intrapersonal Factors as a Possible Predictor of Outcome & 9 & 1 & 10 \\
\hline Client Symptom Severity as a Possible Predictor of Outcome & 10 & 0 & 10 \\
\hline Client Demographics as a Possible Predictor of Outcome & 8 & 1 & 9 \\
\hline Client Interpersonal Factors as a Possible Predictor of Outcome & 6 & 0 & 6 \\
\hline Client Expectations as a Possible Predictor of Outcome & 4 & 1 & 5 \\
\hline Client Diagnosis/Type of Problem as Possible Predictors Outcome & 4 & 0 & 4 \\
\hline Understanding Client Expectations & 3 & 1 & 4 \\
\hline Assessment & & & 42 \\
\hline Scale Development or Validation & 23 & 3 & 26 \\
\hline Understanding Psychopathology/Symptomatology & 14 & 0 & 14 \\
\hline Evidence-based Assessment & 2 & 0 & 2 \\
\hline Intervention & & & 202 \\
\hline Understanding Working Alliance & 32 & 3 & 35 \\
\hline Predictors of Drop-Out & 28 & 4 & 32 \\
\hline Psychotherapy Process & 19 & 4 & 23 \\
\hline Patterns of Response to Psychotherapy & 21 & 1 & 22 \\
\hline Effectiveness of a Specific Treatment(s) & 9 & 7 & 16 \\
\hline Working Alliance as a Possible Predictor of Outcome & 11 & 1 & 12 \\
\hline Effectiveness of Overall Clinic & 10 & 1 & 11 \\
\hline Therapist Experience as a Possible Predictor of Outcome & 10 & 0 & 10 \\
\hline Therapist Intrapersonal Factors as a Possible Predictor of Outcome & 5 & 3 & 8 \\
\hline Number of Sessions as a possible Predictor of Outcome & 6 & 1 & 7 \\
\hline Feedback as a possible Predictor of Outcome & 6 & 0 & 6 \\
\hline Client-Therapist Match on Demographics as possible predictor of & 3 & 2 & \\
\hline Outcome & & & 5 \\
\hline Therapist Interpersonal Factors as Possible Predictors of Outcome & 4 & 1 & 5 \\
\hline Type of Outcome/How to Measure Outcome & 3 & 0 & 3 \\
\hline Therapist Theoretical Orientation as Possible Predictor of Outcome & 2 & 0 & 2 \\
\hline Efficacy (RCTs) & 2 & 0 & 2 \\
\hline Therapist Demographics as a Possible Predictor of Outcome & 1 & 0 & 1 \\
\hline Therapist Expectations as a Possible Predictor of Outcome & 1 & 0 & 1 \\
\hline Therapist Allegiance as Possible Predictor of Outcome & 1 & 0 & 1 \\
\hline Staff and Clinical Training & & & 67 \\
\hline Supervision & 26 & 3 & 29 \\
\hline Clinical Training and Competency & 22 & 8 & $29 *$ \\
\hline Cultural Competence & 6 & 0 & 6 \\
\hline Ethics & 2 & 0 & 2 \\
\hline Interprofessional Learning & 0 & 1 & 1 \\
\hline Research and Research Training & & & 6 \\
\hline Role of Clinic in Research & 2 & 1 & 3 \\
\hline Non-Clinical Research in the Clinic & 2 & 1 & 3 \\
\hline Scientist-Practitioner Model & 0 & 0 & 0 \\
\hline Research Training & 0 & 0 & 0 \\
\hline
\end{tabular}


Note. Clinical Training and Competency includes a study conducted in the USA and Canada, which was therefore included in both columns, but only counted once in the total. 


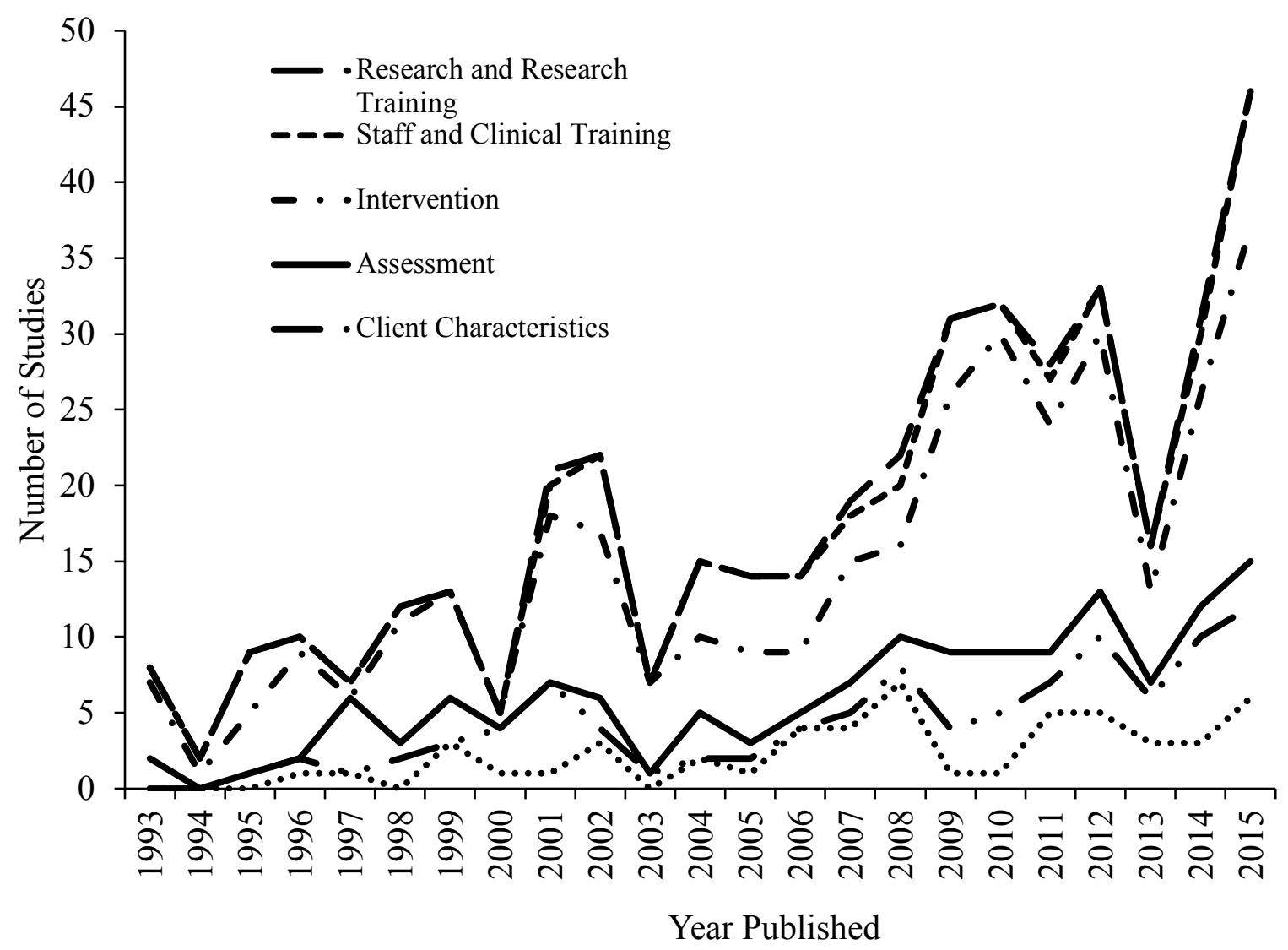

Figure 1. Number of studies publishing research in each topic area between 1993 and 2015 